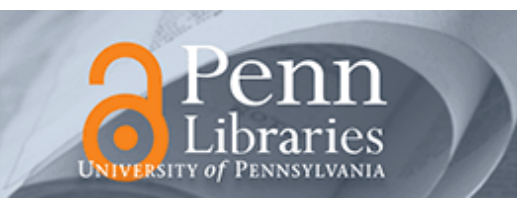

University of Pennsylvania

ScholarlyCommons

2-11-2022

\title{
Same Environment, Stratified Impacts? Air Pollution, Extreme Temperatures, and Birth Weight in South China
}

Xiaoying Liu

University of Pennsylvania, xiaoyliu@sas.upenn.edu

Jere R. Behrman

University of Pennsylvania, jbehrman@sas.upenn.edu

Emily Hannum

University of Pennsylvania, hannumem@soc.upenn.edu

Fan Wang

University of Houston, fwang26@uh.edu

Qingguo Zhao

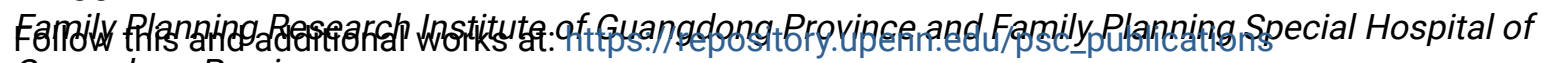
f',angdong Province

Part of the Demography, Population, and Ecology Commons, Family, Life Course, and Society

Commons, Gender and Sexuality Commons, Inequality and Stratification Commons, and the Place and

Environment Commons

\section{Recommended Citation}

Liu, Xiaoying, Jere Behrman, Emily Hannum, Fan Wang, and Qingguo Zhao. 2022. "Same Environment, Stratified Impacts? Air Pollution, Extreme Temperatures, and Birth Weight in South China." University of Pennsylvania Population Center Working Paper (PSC/PARC), 2022-60. https://repository.upenn.edu/ psc_publications/60.

This working paper was published in a journal:

Liu, Xiaoying, Jere Behrman, Emily Hannum, Fan Wang, and Qingguo Zhao. 2021. "Same Environment, Stratified Impacts? Air Pollution, Extreme Temperatures, and Birth Weight in South China." Social Science Research:102691.

https://doi.org/10.1016/j.ssresearch.2021.102691.

This paper is posted at ScholarlyCommons. https://repository.upenn.edu/psc_publications/60

For more information, please contact repository@pobox.upenn.edu. 


\title{
Same Environment, Stratified Impacts? Air Pollution, Extreme Temperatures, and Birth Weight in South China
}

\author{
Abstract \\ This paper investigates whether associations between birth weight and prenatal ambient environmental \\ conditions-pollution and extreme temperatures-differ by 1) maternal education; 2) children's innate \\ health; and 3) interactions between these two. We link birth records from Guangzhou, China, during a \\ period of high pollution, to ambient air pollution (PM10 and a composite measure) and extreme \\ temperature data. We first use mean regressions to test whether, overall, maternal education is an "effect \\ modifier" in the relationships between ambient air pollution, extreme temperature, and birth weight. We \\ then use conditional quantile regressions to test for effect heterogeneity according to the unobserved \\ innate vulnerability of babies after conditioning on other confounders. Results show that 1) the negative \\ association between ambient exposures and birth weight is twice as large at lower conditional quantiles \\ of birth weights as at the median; 2 ) the protection associated with college-educated mothers with \\ respect to pollution and extreme heat is heterogeneous and potentially substantial: between 0.02 and \\ 0.34 standard deviations of birth weights, depending on the conditional quantiles; 3 ) this protection is \\ amplified under more extreme ambient conditions and for infants with greater unobserved innate \\ vulnerabilities.

\section{Keywords} \\ air pollution, birth weight, maternal education, extreme temperatures, China

\section{Disciplines} \\ Demography, Population, and Ecology | Family, Life Course, and Society | Gender and Sexuality | Inequality \\ and Stratification | Place and Environment | Social and Behavioral Sciences | Sociology

\section{Comments} \\ This working paper was published in a journal: \\ Liu, Xiaoying, Jere Behrman, Emily Hannum, Fan Wang, and Qingguo Zhao. 2021. "Same Environment, \\ Stratified Impacts? Air Pollution, Extreme Temperatures, and Birth Weight in South China." Social Science \\ Research:102691. https://doi.org/10.1016/j.ssresearch.2021.102691.
}




\title{
Same environment, stratified impacts? Air pollution, extreme temperatures, and birth weight in south China*
}

\author{
Xiaoying Liu, Jere R. Behrman, Emily Hannum, Fan Wang, and Qingguo Zhao ${ }^{\dagger}$
}

February 11, 2022

\begin{abstract}
This paper investigates whether associations between birth weight and prenatal ambient environmental conditions-pollution and extreme temperatures-differ by 1) maternal education; 2) children's innate health; and 3) interactions between these two. We link birth records from Guangzhou, China, during a period of high pollution, to ambient air pollution ( $\mathrm{PM}_{10}$ and a composite measure) and extreme temperature data. We first use mean regressions to test whether, overall, maternal education is an "effect modifier" in the relationships between ambient air pollution, extreme temperature, and birth weight. We then use conditional quantile regressions to test for effect heterogeneity according to the unobserved innate vulnerability of babies after conditioning on other confounders. Results show that 1) the negative association between ambient exposures and birth weight is twice as large at lower conditional quantiles of birth weights as at the median; 2) the protection associated with college-educated mothers with respect to pollution and extreme heat is heterogeneous and potentially substantial: between 0.02 and 0.34 standard deviations of birth weights, depending on the conditional quantiles; 3 ) this protection is amplified under more extreme ambient conditions and for infants with greater unobserved innate vulnerabilities.
\end{abstract}

JEL: I14, J1,Q53, Q54

*This paper has been accepted for publication at Social Science Research: https://doi.org/10.1016/j.ssresearch. 2021.102691.

$\dagger$ Xiaoying Liu: Population Studies Center, University of Pennsylvania, 3718 Locust Walk, Philadelphia, Pennsylvania, USA; Jere R. Behrman: Departments of Economics and Sociology and Population Studies Center, University of Pennsylvania, 133 South 36th Street, Philadelphia, Pennsylvania, USA; Emily Hannum (corresponding, hannumem@soc.upenn.edu): Department of Sociology and Population Studies Center, University of Pennsylvania, 3718 Locust Walk, Philadelphia, Pennsylvania, USA; Fan Wang: Department of Economics, University of Houston, 3623 Cullen Boulevard, Houston, Texas, USA; Qingguo Zhao: Epidemiological Research Office of Key Laboratory of Male Reproduction and Genetics National Health and Family Planning Commission, Family Planning Research Institute of Guangdong Province, Guangzhou, Guangdong, China. This paper is part of the project "Prenatal Air Pollution Exposures and Early Childhood Outcomes," which is supported by a grant from the Penn China Research and Engagement Fund (PIs: Behrman and Hannum) and by National Science Foundation Grant 1756738 (PI: Hannum). The authors also gratefully acknowledge support from the University of Houston Research Fund and, for coverage of Wang's time, Scholar Grant GS040-A-18 from the Chiang Ching-Kuo Foundation. We thank Yu Xie and James Raymo for the opportunity to receive feedback at the Princeton Research in East Asian Demography and Inequality Seminar. We also thank Guy Grossman, Harsha Thirumurthy, Heather Schofield, and other participants in the Penn Development Research Initiative (PDRI) Seminar for comments. Finally, the authors appreciate the helpful feedback provided by anonymous reviewers. 


\section{Keywords}

Keywords: air pollution, birth weight, maternal education, extreme temperatures, China

\section{Highlights}

1. We test maternal education as an effect modifier in associations between air pollution/extreme temperature and birth weight.

2. We link birth records to environmental data from Guangzhou, China during a period of high and variable air pollution.

3. Infants with unobserved vulnerabilities - at lower conditional quantiles of birth weightface more risk from ambient exposures.

4. The protection associated with college-educated mothers with respect to pollution and extreme heat is substantial.

5. Protection is amplified under more extreme ambient conditions and for infants with greater unobserved innate vulnerability. 


\section{Introduction}

Ambient environmental conditions, including both air pollution and temperature, have been associated with adverse birth outcomes in a number of settings, though findings for temperature remain limited (Cho 2020; Currie 2013; DeCicca and Malak 2020; Klepac et al. 2018; Kloog et al. 2015; Melody et al. 2019; Shah and Balkhair 2011; Stieb et al. 2012; Zhang, Yu, and Wang 2017). However, some newborns may be more vulnerable than others to the same ambient environmental conditions, due to inequalities in at least two dimensions. First, the pathway from ambient conditions to adverse birth outcomes may vary with maternal education. For example, children in utero with less-educated mothers may be more vulnerable than those of moreeducated mothers if their mothers have poorer access to living, work, transportation, and leisure spaces with indoor air filtration and temperature regulation, or if they have limited knowledge of or resources for mitigation strategies. ${ }^{1}$ Second, babies' different innate health vulnerabilities may relate to unequal outcomes in the same environmental context. The relevance of these two dimensions may be particularly great in more extreme environments, and the protective effects of maternal education may be more pronounced for infants with greater unobserved innate vulnerabilities.

This paper investigates two key questions. First, do children of expectant mothers in common ambient pollution and temperature environments experience different birth outcomes, according to their mothers' education? In other words, are there protective effects of maternal education? Second, are protective effects of maternal education more pronounced among infants with greater unobserved vulnerabilities — those poorer innate health? We employ mean and conditional quantile regressions to study these questions jointly, with data from a fairly high-pollution environment, for three key dimensions of ambient environmental exposures: air pollution,

\footnotetext{
1 Behavioral strategies that respond to extreme pollution and temperature, undertaken by those who can afford them, have been documented in China. For example, Zhang and Mu $(2018,518)$ estimated that a 100-point increase in the Air Quality Index in China was associated with a 70.6\% increase in expenditures on anti-PM $\mathrm{P}_{2.5}$ masks and a 54.4\% increase for all types of masks. Using evidence from air-purifier sales linked to city data and household-income data, Ito and Zhang (2020) show that higher-income households in China have significantly higher marginal willingness to pay for clean air compared with lower-income households. With regard to temperature, Yu, Lei, and Wang (2019) find that while urban households respond to extreme temperatures via increased energy consumption or air conditioner purchases, rural households are unresponsive to temperature fluctuations. The authors attribute this difference in mitigation practices to a lack of resources in rural households.
} 
extreme heat, and extreme cold.

We focus on birth weight as the outcome of interest. Birth weight is a consistent correlate of health and other socio-economic outcomes across the life course (Behrman and Rosenzweig 2004; Behrman, Xiong, and Zhang 2015; Black, Devereux, and Salvanes 2007; Torche and Conley 2016). We utilize a database of every singleton live birth recorded every day between 2009 and 2011 in one city district with more than one million residents and fairly high air pollution in south China, for a total of 53,879 birth records. We link the births data to daily air pollution and meteorological data spanning the entire prenatal periods for these births. We exploit daily variations in air pollution levels that are caused mainly by random changes in atmospheric conditions and pollutant emissions (He, Liu, and Salvo 2019; Janke 2014). The high frequency of measurement of air pollution allows us to control for year-by-month fixed effects, which capture time patterns that might reflect seasonal effects and changes in economic conditions over time that are shared commonly across the city. We calculate daily mean exposure estimates for three monitored air pollutants, namely particulate matter $\left(\mathrm{PM}_{10}\right)$, sulfur dioxide $\left(\mathrm{SO}_{2}\right)$, and nitrogen dioxide $\left(\mathrm{NO}_{2}\right)$, and also generate a composite index of potential exposure to all three air pollutants during pregnancy. We also calculate the percentages of days during pregnancy that were extremely hot or cold, to control for deviations in weather from a common seasonal trend that can also have impacts on birth outcomes.

To address our main research questions, we interact a binary variable indicating whether mothers have university education with measures of pollution and extreme temperature exposure to estimate effect modifications-protective effects-associated with maternal education, after adjusting for infant sex, a quadratic function of maternal age, parity, rainfall, and time trends. To our knowledge, this is the first paper to study protective effects jointly in the context of pollution and extreme temperature. Prior research has shown that pollution and extreme temperature might be independently important factors. However, given the potential correlation between them, it is important to analyze protective effects in a joint framework.

Further, we allow for the protective effects of maternal education to be heterogeneous across conditional quantiles of birth weight, which map to infants' unobserved innate health vulnerabilities. While the literature on quantile regressions has suggested that birth weight is 
an ideal variable on which to apply conditional quantile methods (Koenker and Hallock 2001), this analysis is one of the first to adopt conditional quantile methods to analyze the protective effects of maternal education on birth weight. ${ }^{2}$ Following the literature on conditional quantile estimation (Abrevaya 2001; Abrevaya and Dahl 2008; Arias, Hallock, and Sosa-Escudero 2001), conditional on observed maternal characteristics, time trends, and environmental exposures, we interpret newborns to the left of the conditional distribution of birth weight as having higher levels of unobserved innate health vulnerabilities. ${ }^{3}$ We organize this paper as follows. Section 2 gives the background and research questions, Section 3 discusses data and methods, Section 4 gives and discusses the results, and Section 5 is a discussion and conclusion.

\section{Background and Research Questions}

\subsection{Air Pollution and Birth Outcomes}

Studies have traced associations between prenatal exposure to various kinds of air pollutants and adverse birth weight and other birth outcomes (Klepac et al. 2018; Melody et al. 2019; Shah and Balkhair 2011; Stieb et al. 2012). Currie and Walker (2011) found that the introduction of electronic toll collection greatly reduced both traffic congestion and vehicle emissions near highway toll plazas and reduced prematurity and low birth weight among mothers within two kilometers of toll plazas by $10.8 \%$ and $11.8 \%$, respectively, relative to mothers two to ten kilometers from toll plazas. Hao et al. (2016) analyzed birth records between 2002 and 2006 from the Georgia Department of PUblic Health and found that all traffic-related pollutants, including $\mathrm{NO}_{2}$ and $\mathrm{PM}_{2.5}$, were associated with preterm birth. DeCicca and Malak (2020) analyzed the impact of a policy that mandated the reduction of power-plant emissions in the eastern United States. The policy greatly reduced emissions of $\mathrm{SO}_{2}$ and $\mathrm{NO}_{\mathrm{x}}$, which are the

2 Using Chinese data from 16 counties from 2014 to 2018, Wu et al. (2021) study the effects of $\mathrm{PM}_{2.5}$ on birth weight in a conditional quantile context. They estimate heterogeneous effects by maternal educational status as well. In contrast to the current paper, their analysis does consider extreme temperature exposures.

3 An alternative to the conditional quantile approach is to use observed variables that measure innate vulnerabilities of children, which has the benefit of clarifying observed variables that might be useful for targeted policies. The benefit of the conditional quantile approach is that it is able to capture the full spectrum of potential sources of vulnerabilities, not just observed characteristics, and does not impose restrictions on the differences in impact magnitudes between less and more vulnerable individuals. 
major precursors for $\mathrm{PM}_{2.5}$. Their results suggest that the policy reduced the proportion of newborns downwind born prematurely and experiencing low birth weight, and reduced infant mortality for "high-risk" pregnancies associated with observed maternal health conditions such as diabetes, hypertension or eclampsia. Their conceptualization of risk using observed maternal health conditions is related to but distinct from our focus on unobserved innate vulnerabilities of babies themselves. Liu et al. (2022) exploited exogenous air quality improvement during the Guangzhou Asian Games period to estimate the effects of $\mathrm{PM}_{10}, \mathrm{NO}_{2}$, and $\mathrm{SO}_{2}$ on birth outcomes. They find that effects vary by pregnancy trimesters, sex, and maternal age.

A large-scale study in Brisbane, Australia, indicated that pregnancy exposures to $\mathrm{PM}_{2.5}$, $\mathrm{SO}_{2}, \mathrm{NO}_{2}$, and ozone $\left(\mathrm{O}_{3}\right)$ were associated with increased risks of low birth weight, as well as pre-term birth (Chen et al. 2018). Chen and Ho (2016) find that incense burning is associated with lower birth weight in boys, and their quantile regression also suggests that the negative associations are larger among the lower quantiles of birth outcomes.

Focusing on particulate matter, a recent United States study analyzed birth certificates data for the period 1999 to 2007 and found significant birth weight effects associated with gestational exposures to one form of coarse particulate matter $\left(\mathrm{PM}_{10-2.5}\right)$ (Ebisu, Berman, and Bell 2016). Similarly, a study of 7,772 mothers in the Netherlands between 2001 and 2005 found that $\mathrm{PM}_{10}$ exposure during pregnancy was inversely associated with birth weight (Hooven et al. 2012). The World Health Organization (WHO) Global Survey on Maternal and Perinatal Health study examined whether outdoor $\mathrm{PM}_{2.5}$ was associated with adverse birth outcomes among 22 countries from 2004 through 2008 (Fleischer et al. 2014). Results showed that across all countries, $\mathrm{PM}_{2.5}$ was not associated with preterm birth, but was associated with low birth weight. In China, the country with the greatest $\mathrm{PM}_{2.5}$ range among those studied, preterm birth and low birth weight both were associated with the highest quartile of $\mathrm{PM}_{2.5}$ (Fleischer et al. 2014). $\mathrm{PM}_{10}$ and $\mathrm{PM}_{2.5}$ concentrations are highly correlated in China-especially in southern China (Zhou et al. 2016). Studies in Lanzhou, China and Wuxi, China also indicated that prenatal exposure to $\mathrm{PM}_{10}$ increases the risk of preterm birth (Han et al. 2018; Zhao et al. 2015).

Several recent reviews have synthesized findings. Melody et al. (2019) conducted a systematic review of acute air quality change studies and found mixed results: there was some evidence that 
maternal exposure to acute changes in air quality of short-to medium-term duration increased the risk of fetal growth restriction and preterm birth, but the relationship for other adverse obstetric or neonatal outcomes was less clear. Shah and Balkhair (2011) conducted a broader systematic review of studies of air pollution exposure and birth outcomes. This review suggested that maternal exposure to $\mathrm{SO}_{2}$ was associated with preterm birth, exposure to $\mathrm{PM}_{2.5}$ was associated with low birth weight, preterm birth, and small-for-gestational-age birth, and exposure to $\mathrm{PM}_{10}$ was associated with small-for-gestational-age birth. Evidence for $\mathrm{NO}_{2}$ was inconclusive. Another systematic review and meta-analysis of 62 studies indicated that pooled estimates of effects generally suggested associations between carbon monoxide $(\mathrm{CO}), \mathrm{NO}_{2}$, and particulate matter and pregnancy outcomes, but also that there was a high degree of heterogeneity among studies (Stieb et al. 2012). ${ }^{4}$

A recent paper systematically reviewed Chinese and English publications on links between air pollution exposure and adverse pregnancy outcomes in China (Jacobs et al. 2017). The authors reported that $\mathrm{SO}_{2}$ was consistently associated with lower birth weight and more preterm births and $\mathrm{PM}_{10}$ was consistently associated with congenital anomalies. Results for $\mathrm{NO}_{2}$ were inconsistent, and the authors concluded that further studies were required on the effects of $\mathrm{PM}_{2.5}$, ozone $\left(\mathrm{O}_{3}\right)$, and carbon monoxide $(\mathrm{CO})$. While a number of the studies adjusted for education or other measures of socioeconomic status, the review does not report tests of effect modification by these stratifiers. A more recent study in Guangdong Province (Liu et al. 2019), which covered the period of 2014 to 2015, reported, among other significant findings, associations with low birth weight for $\mathrm{PM}_{2.5}, \mathrm{PM}_{10}, \mathrm{SO}_{2}, \mathrm{NO}_{2}$, and $\mathrm{O}_{3}$ in the first month and with $\mathrm{PM}_{2.5}, \mathrm{PM}_{10}, \mathrm{NO}_{2}$, and $\mathrm{O}_{3}$ in the last month of pregnancy.

\subsection{Extreme Temperature and Birth Outcomes}

Extreme temperature events are increasing in frequency, duration, and magnitude (World Health Organization 2018b). For example, between 2000 and 2016, the number of people exposed to

\footnotetext{
${ }^{4}$ Early pollution exposures may endure in their impact. Currie et al. (2014) summarized studies from developed and a few developing countries on the short- and long- term effects of in-utero and early-life exposure to pollution. The review highlighted evidence that exposure to pollution significantly impacted a variety of birth, childhood, and later-life outcomes.
} 
heat waves increased by around 125 million (World Health Organization 2018b). Temperature extremes have been linked to significant reductions in human health, including height and birth weight (Deschênes 2014; Deschênes, Greenstone, and Guryan 2009; Ogasawara and Yumitori 2019). However, to date, evidence about extreme temperatures and birth outcomes remains limited (Basu et al. 2018; Kloog et al. 2015; Zhang, Yu, and Wang 2017), and that which is available is somewhat mixed. For example, a recent analysis of data from Korea found no significant temperature effect on birth outcomes (Cho 2020). A 2017 systematic review concluded that the evidence linking preterm birth and low birth weight to ambient temperature was still very limited and not conclusive, though there were more examples of adverse estimated effects for high temperatures than for low temperatures (Zhang, Yu, and Wang 2017). A 2020 systematic review covered papers about the associations of air pollution and heat exposure with preterm birth, low birth weight, and stillbirth in the United States (Bekkar et al. 2020). Only three papers were identified that considered heat and birth weight, but all found significant risk. One, a paper that analyzed 220,572 singleton births for the years 2002 to 2008 from 12 United States sites, found that whole-pregnancy cold or hot temperature increased term low birth weight risk (Ha et al. 2017). A second paper, conducted among 43,629 full-term but low birth weight babies and 2,032,601 normal-weight babies in California for the period 1999 to 2013, found that higher long-term apparent temperature exposure was associated with term low birth weight (Basu et al. 2018). The third reviewed paper, conducted among births in Massachusetts from 2000 through December 2008 (Kloog et al. 2015), showed decreased birth weight with increased air temperature.

In China, a study in the city of Guangzhou found that exposure to either low or high temperatures during pregnancy was associated with an increased risk of preterm birth (He et al. 2016). A near-national scale study by $\mathrm{Hu}$ and $\mathrm{Li}$ (2019) linked extreme heat exposure during pregnancy to significant reductions in multiple dimensions of adult welfare. The authors report that adults who experienced an additional day of high temperature during their prenatal periods, on average, attained 0.02 fewer years of schooling, had a higher risk of illiteracy by $0.18 \%$, showed a $0.48 \%$ decrease in standardized word-test scores, and were shorter by 0.02 centimeters. 


\subsection{Same Ambient Environment, Different Impacts}

There is reason to believe that the effects of ambient air pollution and temperature exposures might vary by maternal education. First, because more-educated mothers are likely to enjoy better material resources or better knowledge compared to less-educated mothers, more-educated mothers may well adopt mitigation strategies and thus experience lower realized exposures in the same ambient air pollution and extreme temperature environments. Second, because bettereducated mothers, as a group, are likely to have better nutrition and health care access compared to less-educated mothers, they may have more physical capacity to weather the same realized exposures to pollution and extreme temperatures.

There is at least suggestive evidence that the same ambient environment might be experienced differently for more and less economically vulnerable groups, such as groups defined by parental education. ${ }^{5}$ In a study in Georgia, Hao et al. (2016) found that associations of traffic-related pollutants, including $\mathrm{NO}_{2}$ and $\mathrm{PM}_{2.5}$, with preterm birth tended to be stronger for mothers with low educational attainment. A study in Korea of multiple air pollutants showed mixed results, but some evidence of socioeconomic disparities in the effects of full-pregnancy exposure at the lowest conditional quantiles of birth weight (Lamichhane et al. 2020). Heo, Fong, and Bell (2019) conducted a systematic review of papers assessing the effects of particulate matter on birth outcomes from 2000 to 2019 and found suggestive evidence that the risk posed was greater for babies of mothers with lower educational attainment for preterm birth and low birth weight.

However, in a recent review of epidemiological literature about ambient air pollution and birth weight, Westergaard and her colleagues (2017) identified only a small number of studies that addressed effect modification by maternal education status. With regard to temperature effects, Zhang, Yu, and Wang (2017) call for more attention to the possibility of individual effect modifiers; maternal education is one important potential stratifier (see Basu et al. (2018) and Son et al. (2019) for inconsistent findings on maternal education as an effect modifier). Generally, the resources associated with maternal education might be more likely to be brought to bear

\footnotetext{
5 Positive associations between maternal education and birth outcomes, including birth weight but also preterm birth and birth length, have been described in a number of studies (Abel, Kruger, and Burd 2002; Ballon et al. 2019). Studies in the United States have often found significant differences in birth weight for infants borne in more disadvantaged and segregated socio-economic communities with distressed physical environments (Grady 2006; Kothari et al. 2016).
} 
under extreme conditions of pollution and temperature, which would exacerbate the maternal protective effect under these conditions. A similar logic suggests that the protective effects of maternal education with respect to pollution and extreme temperature might be most pronounced for infants with greater unobserved innate vulnerabilities.

A recent study from China also examines the heterogeneous association between air pollution and birth weight — but does not consider extreme temperatures—using quantile regression and finds that more pronounced effects were observed in lower and intermediate quantiles (Wu et al. 2021). This paper observed stronger associations among well-educated mothers. Although the paper uses data from 16 counties across China during the period of 2014 to 2018, it does not control for county-specific time trends that may capture local policy variations and trends in the economic environment that can also affect birth outcomes. Additionally, Wu et al. (2021) consider only full-term births. Except for Wu et al. (2021), we have not found other studies of pollution and birth weight that investigate variability in the protective effect of maternal education using a conditional quantile approach.

A handful of studies in the United States have used conditional quantile approaches to consider heterogeneous vulnerability to ambient pollution exposure. A study of $\mathrm{PM}_{2.5}$ in California (Schwarz et al. 2019) shows a tendency of somewhat larger negative associations with outcomes at the lowest conditional quantiles, though primarily among the non-Hispanic Black population. A study of $\mathrm{PM}_{2.5}$ in Massachusetts (Fong et al. 2019) found that the negative association between $\mathrm{PM}_{2.5}$ and birth weight was larger in magnitude at the lower conditional quantiles of birth weight than in the higher quantiles. In contrast, a study in Atlanta (Strickland et al. 2019) showed larger effects for several pollutants at higher conditional quantiles. While results are mixed, all of these studies suggest the potential value in testing for heterogeneity in associations across the distribution of children's unobserved innate vulnerabilities at birth, along the conditional distribution of birth weight.

\subsection{Research Questions}

Using a case study of three years of singleton live births in one district in Guangzhou, China, we study the protective effect of mothers' education with respect to pollution and extreme 
temperature exposure. Specifically, we consider the association between expectant mothers' college educational attainment and their children's birth weight and allow the college educational gradient to be heterogeneous at different ambient pollution and extreme temperature levels. By including pollution and extreme temperature in the same specifications, we are able to isolate the separate relationships between these correlated but distinct ambient environmental factors and birth outcomes. Conditional on environmental exposures, we also allow the educational gradient to be heterogeneous for children with different unobserved innate vulnerabilities.

Our analysis relaxes the restrictions imposed by common regression frameworks on how socioeconomic factors might impact child-birth outcomes in a setting where mothers are exposed to high levels of negative environmental factors. A common regression framework includes educational status as an additive variable (for example, see Koenker and Hallock (2001) (birth weight) and Hanandita and Tampubolon (2015) (BMI) in the context of quantile regressions; see Bharadwaj and Eberhard (2008) in the context of mean regressions). In the context of (conditional) mean regressions, this framework means that the educational gradient in birth weight is constant across levels of environmental exposure levels. By interacting mothers' education with multiple potential negative environmental factors, we allow for the educational gradient in child birth outcomes to be magnified at different rates depending on how negative environmental factors jointly worsen. Furthermore, by estimating education-environment interactions separately at different conditional quantiles of birth weight, we allow the educational gradient to have different slopes by quantiles of unobserved innate vulnerabilities of babies. The rich heterogeneous relationships allow for a nuanced look at the potential protective effects of maternal college education in ameliorating negative environmental effects.

\section{Data and Methods}

\subsection{Study Site}

The study site for this project is Guangzhou, which is the capital city of Guangdong Province in south China, in the Pearl River Delta. Guangzhou, along with several other cities in Guangdong as well as Hong Kong and Macau, is part of the rapidly-developing "Greater Bay Area" mega- 
lopolis. The region is wealthy, with Shenzhen and Guangzhou, respectively, ranked third and fourth highest in city GDP in China, after Beijing and Shanghai (Buchholz 2019). Guangzhou has a typical subtropical climate, with very mild winters and hot, humid summers. The annual mean temperature in Guangzhou is around 22 degrees Celsius (Climate-Data.org 2020). In recent decades, Guangzhou has experienced increases in mean annual temperatures and in the frequency, duration, and intensity of heat waves (Zhang et al. 2017). Extreme heat events are a particularly significant threat to human health due to a combination of the subtropical climate and urban heat-island effects exacerbated by rapid population growth in recent years (Zhang et al. 2017). Recent studies in Guangzhou have linked maternal heat exposures to preterm births (He et al. 2016; Wang et al. 2020). At the same time, and perhaps somewhat counter-intuitively in a subtropical climate, cold spells in Guangzhou carry health risks. For example, cold spells have been linked to increased mortality risk for most categories of deaths and to heightened risk of preterm birth (Chen et al. 2021; He et al. 2016), possibly due to the lack of widespread access to central heating. As a major city in south China, Guangzhou is a data point that is potentially relevant to other urban settings in south China, and possibly parts of Southeast Asia, characterized by broadly similar climates, high levels of pollution, and economic conditions.

South China has had less air pollution than north China, but as an economic development center, Guangzhou has been one of the most polluted cities in the region. Recent studies in Guangzhou have linked air pollution to respiratory distress syndrome and to student respiratory illness and absenteeism, especially for younger students (Chen, Guo, and Huang 2018; Lin et al. 2018). Importantly, Guangzhou has a well-established and extensive air-quality monitoring system with both air pollution indices and individual pollutant concentrations available at the city level.

Figure 1 shows levels of air pollution in Guangzhou from 2008 to 2011 for three monitored pollutants: $\mathrm{PM}_{10}, \mathrm{SO}_{2}$, and $\mathrm{NO}_{2}$. The levels of pollution depicted in Figure 1 reflect substantial improvements in Guangzhou's air quality compared to prior years. In the early 2000s, the local government implemented progressive air-quality control efforts that included closing down low-efficiency coal-power plants and enforced installation of desulfurization facilities (Zhong et al. 2013). Even with improvements, annual mean air pollution in Guangzhou during this 
period exceeded the WHO standard for $\mathrm{PM}_{10}$ : a $20 \mu \mathrm{g} / \mathrm{m}^{3}$ annual mean. Further, $66.4 \%$ of days surpassed the 24-hour mean standard for $\mathrm{PM}_{10}$ of $50 \mu \mathrm{g} / \mathrm{m}^{3}$ and $76 \%$ of days surpassed the $\mathrm{SO}_{2}$ standard of $20 \mu \mathrm{g} / \mathrm{m}^{3}$ (World Health Organization 2018a). There is strong seasonality in all three types of air pollution, with more severe air pollution in the winter than in the summer.

\subsection{Data}

We link three forms of data for this analysis: birth certificate data, air pollution data, and meteorological data.

\subsubsection{Birth Certificate Data}

We have access to birth certificate data representing all births that took place in one district in the center city of Guangzhou on every day in the years 2009 to 2011. It is the responsibility of the parents or the family concerned to register all births within 15 days after birth (Lin et al. 2015). We elected to use birth certificate data from one particular district in the city because of the availability only for that district of information on maternal education. In addition to maternal education, the birth certificate data include information about gestational age based on reported last menstrual period and confirmed by ultrasound scanning, stillbirth, birth weight, birth length, sex, parity, Apgar scores, and mother's age, occupation, rural/urban residence status, and number of pregnancies. 6

\subsubsection{Air Pollution Data}

Our interest lies in tracing different experiences in a common ambient environment, and we operationalize this idea with a city average pollution measure. Our data source for air pollution is the Guangzhou Environmental Bureau, which reports the daily average levels of three monitored "criteria" air pollutants, $\mathrm{PM}_{10}, \mathrm{NO}_{2}$, and $\mathrm{SO}_{2}$, at the city level during the period 2005 to 2011. These pollutants are measured according to the National Standard (Guo Biao) GB3095-1996. These are the only three pollutants for which data were collected until 2014. These are measures

\footnotetext{
6 Birth certificates also contain information on infant health and neonatal mortality.
} 
of ambient conditions, rather than individual pollution exposure measures. ${ }^{7}$ For our research question, we want ambient measures because women with different levels of education may be able to alter their individual exposure so that individual exposure data might miss some of the impacts of maternal education.

\subsubsection{Meteorological Data}

We used the universal thermal climate indices (UTCI) from Copernicus and the European Centre for Medium-Range Weather Forecasts (ECMWF) to measure extreme temperatures (Copernicus and European Centre for Medium-Range Weather Forecasts 2020). The UTCI, a thermal comfort indicator based on human heat-balance models, is designed to be applicable in all seasons and climates and for all spatial and temporal scales (Copernicus and European Centre for MediumRange Weather Forecasts 2020). The UTCI is a one-dimensional index that reflects "the human physiological reaction to the multidimensionally defined actual outdoor thermal environment" (Bröde et al. 2012, 481). Scores can be classified into ten thermal stress categories, ranging from extreme cold stress to extreme heat stress (Copernicus and European Centre for Medium-Range Weather Forecasts 2020). In a subtropical, humid environment such as Guangzhou, this index provides a wider range of variation than ambient temperature. These data have high spatial and temporal resolution, with measurement gridded at $0.25^{\circ} \times 0.25^{\circ}$ and at hourly frequency. We obtain the measurement at the grid closest to the center city of Guangzhou and calculate the daily average from 2008 to 2011.

Finally, we use 24-hour accumulated rainfall from the same grid for the same period. We control for rainfall because it may be correlated with pollution and temperature and may have effects on birth outcomes. ${ }^{8}$ Accumulated rainfall is calculated from observed rainfall data, and comes from the National Oceanic and Atmospheric Administration (2020), as distributed by Raspisaniye Pogodi Ltd. (2020).

\footnotetext{
7 Pregnant women may come from any district in the city. There is precedent for using city-average measures of pollution. Zhao et al. (2015) report seven studies that used city-level averages of $\mathrm{PM}_{10}$ (Darrow et al. 2009; Hansen et al. 2006; Jiang et al. 2007; Sagiv et al. 2005; Schifano et al. 2013; Suh et al. 2009; Zhao et al. 2011).

8 We provide details on how we acquire and process ECMWF data in Appendix B.
} 


\subsection{Analytic Sample}

We begin with birth-certificate data for all live births $(67,108$ or $99.1 \%$ of all births $)$ in the district for the period 01 January 2009 to 31 December 2011. To avoid fixed-cohort bias, ${ }^{9}$ we delete births within this period with conception dates earlier than 14 July 2008 and those with conception dates later than 15 February 2011, as gestational age varies between 171 and 319 days, which leaves 58,827 observations. We exclude observations with birth weight less than 500 grams (17 observations dropped), or birth length less than 28 centimeters or longer than 60 centimeters (51 observations dropped). We further restrict our sample to include only those with observed gestational age (855 observations without gestational age dropped) and only live singleton births. ${ }^{10}$ We further removed those registered with rural residence (949 observations, or $1.73 \%$ of the sample). In the end, our analytic sample consists of 53,879 live singleton births $\left(15,068\right.$ born in $2009,20,368$ born in 2010, and 18,443 born in 2011). ${ }^{11}$

\subsection{Measurement}

Table 1 contains summary statistics for all variables employed in the analysis. Below, we describe our variables.

9 Fixed-cohort bias emerges when a sample consists of births during a fixed period-this approach will include only the longer pregnancies at the start of the study and only the shorter pregnancies at the end of the study. This has the potential to bias studies of environmental exposures (Strand, Barnett, and Tong 2011).

${ }^{10}$ Because there is no information on the number of multiple births, we count duplicate observations in terms of all observed maternal and paternal characteristics (including mother's birthdate, parity, number of previous pregnancies, maternal occupation, maternal education, paternal education, gestational age, and an indicator of high risk levels) as well as birthdate of the baby, and treat the observations with one duplicated case as twins (3.90\% of 57,108 observations) and those with two duplicated cases as triplets ( $0.08 \%$ of 57,108 observations) and those with three duplicated cases as quadruplets ( $0.01 \%$ of 57,108 observations).

${ }^{11}$ In Appendix Section A.3, we estimate the model after restricting the analytic sample to only those with more than 36 weeks of gestational age. 


\subsubsection{Birth Weight and Other Birth Outcomes}

Our study focuses on birth weight. ${ }^{12}$ Birth weight is reported in grams. The mean birth weight is 3,182 grams and the standard deviation is 473 grams. Babies of mothers with a college degree have, on average, a 46 gram greater birth weight than babies of mothers with at most a high school degree $(\mathrm{p}=0.00)$.

\subsubsection{Air Pollution}

We obtained data on three criteria pollutants, $\mathrm{PM}_{10}, \mathrm{NO}_{2}$, and $\mathrm{SO}_{2}$, observed at all monitoring stations in Guangzhou from the Guangzhou Environmental Bureau. A small number of observations with missing data are replaced with moving averages for the four preceding and four following days. We calculate the average level of all monitoring stations from the four contiguous districts located in the center of the city, one of which is where our birth data is sourced. ${ }^{13}$ Between the years 2009 and 2011, by our estimates, central Guangzhou's air pollution far exceeded the safety standards set by the WHO, with annual mean concentrations of $\mathrm{PM}_{10}$ of $75.9 \mu \mathrm{g} / \mathrm{m}^{3}$ in 2008 , $74.4 \mu \mathrm{g} / \mathrm{m}^{3}$ in 2009, $71.2 \mu \mathrm{g} / \mathrm{m}^{3}$ in 2010 and $69.6 \mu \mathrm{g} / \mathrm{m}^{3}$ in 2011. The WHO safety standard for $\mathrm{PM}_{10}$ is that the annual mean should not exceed $20 \mu \mathrm{g} / \mathrm{m}^{3}$ (World Health Organization 2018a). Seasonal variation is especially significant. For example, the daily mean for $\mathrm{PM}_{10}$ is $49.2 \mu \mathrm{g} / \mathrm{m}^{3}$ in July, on average, but $103.3 \mu \mathrm{g} / \mathrm{m}^{3}$ in December, during the period covered by this study.

We exploit the temporal variation in daily air pollution and the variation in pregnancy timing for identification. We summarize over the duration of pregnancy the daily average level of each pollutant to calculate the accumulated total potential exposure during pregnancy for each individual. However, this approach suffers from a potential problem-it generates a spurious inverse correlation between adverse birth outcomes and accumulated air pollution levels because a shorter gestational age implies a shorter pregnancy and therefore smaller accumulated air

\footnotetext{
${ }^{12}$ Our analysis in the main text of the paper focuses on conditional mean and conditional quantile regressions for birth weight. In Appendix Section A.4, we present results based on the binary outcome variables. For the binary outcomes, low birth weight is 1 if birth weight is under 2500 grams, preterm equals to 1 if gestational age is smaller than 37 weeks, and small-for-gestational-age is defined as 1 for those with birth weight under $10 \%$ in sex- and gestational-age- specific distribution. We use the cutoffs listed in Zhu et al. (2015) as references.

13 Table 1 provides $\mathrm{PM}_{10}$ summary statistics from all city districts as well as from the four center-city districts. We use the center-city districts data for estimation. In Appendix Section A.2, we present robustness checks where we use all city districts pollution data.
} 
pollution exposure. We avoid this spurious relationship by dividing the accumulated levels of each pollutant during pregnancy by each woman's pregnancy duration to get a daily mean level of exposure during pregnancy.

Because pollutants tend to co-vary, we conduct principal component analysis of the three pollutants' daily mean potential exposures during pregnancy and adopt the first principal component, which accounts for $86 \%$ of the total variance, as a composite index of pollution. ${ }^{14}$ We focus on results for our particulate matter measure- $\mathrm{PM}_{10}$ - in the main text, and comment briefly on similar findings using the composite pollution index. Detailed results using the composite measure are included in an appendix.

Substantial individual variation in potential pollution exposure comes from variation in pregnancy timing. As pollution is usually higher in winter than in summer, those whose pregnancies occur mainly in the winter have higher ambient pollution exposure than those whose pregnancies occur mainly in the summer. Moreover, pregnancies in earlier years on average have higher ambient pollution exposure than those in later years, as a result of air-quality improvement over time. In the Guangzhou data, there is a possibly counterintuitive pattern in which mothers with at least a college degree have higher potential air pollution exposure during their pregnancies than mothers with at most a high school degree (as shown in Table 1). This pattern emerges because mothers with at most a high school degree, a category that includes many migrant workers from rural areas, are more likely to marry and conceive in January and February, around Chinese New Year. Figure 3 shows that, after controlling for conception yearby-month fixed effects, the distributions of ambient air pollution exposure are not significantly different between the two maternal-education groups. ${ }^{15}$

\footnotetext{
${ }^{14}$ We adopt principal component analysis as a robustness check to investigate whether a more comprehensive air pollution index shows a consistent pattern of contribution to adverse birth outcomes. However, we are also aware that results from the principal component analysis may not be extrapolated to other places as different cities may have different compositions and interactions of air pollutants.

${ }^{15}$ Individuals of different socioeconomic backgrounds may differ in their capacities to choose where to live and work based on air quality and to adopt mitigation strategies such as wearing masks or installing air filters. These are possible pathways connecting a common ambient environment to different impacts. Available data do not permit measurement of realized individual-level air pollution exposures.
} 


\subsubsection{Extreme Temperature}

We set a cutoff for defining extreme temperatures by creating a local reference dataset comprised of the nine years of records of daily mean UTCI that immediately preceded the dates of our study. We define extreme low and high temperatures, respectively, by generating cut-points marking the bottom $1 \%$ of the distribution of the reference dataset, at -0.87 degrees Celsius, and the top $1 \%$ of the reference dataset, at 34.23 degrees Celsius. Each woman's exposure to extreme temperatures is defined by the proportion of days during pregnancy with daily mean UTCI under or above the cut-off temperatures. Extreme cold and hot temperatures defined in this way correspond to ECMWF categories of moderate cold stress (defined as -13 to 0 degrees Celsius) and strong heat stress (defined as 32 to 38 degrees Celsius). Although air conditioning had become widespread in Guangzhou by the time of the study period, heating in winter was not widely available, which is important for understanding any observed effects of cold stress in this region. Using our definitions, pregnant women in the sample, on average, spent $1.70 \%$ of their pregnancy duration (4.6 days) exposed to extreme cold and $1.73 \%$ of the duration of their pregnancy (4.7 days) exposed to extreme heat.

We perform sensitivity analyses with a less stringent definition of extreme temperatures, using a $2.5 \%$ cutoff to define extreme cold and extreme heat (at 2.52 degrees Celsius and 33.56 degrees Celsius, respectively). Using this alternative definition, on average, pregnant women in the sample spent $4.40 \%$ (11.9 days) of their pregnancy duration in extreme cold and $3.73 \%$ of their pregnancy duration (10.2 days) in extreme heat. Table 2 presents additional distributional details of the extreme heat and cold measures. Figure 2 presents the time-series of daily mean UTCI between the years 2008 and 2011.

\subsubsection{Maternal Education}

We code mothers' education in two categories: high school and below (0) and college and above (1). In our analytic sample, 17,967 (33\%) report college attainment. This sample of mothers from the center of the most developed metropolitan city in south China is highly educated. Recent census figures for the population ages six and above in Guangdong Province indicate a $16 \%$ rate of tertiary attainment; rates are higher for China's wealthiest province-level cities 
(Beijing, 42\%, and Shanghai, 34\%). ${ }^{16}$

\subsubsection{Control Variables}

Pregnancy risks associated with advanced maternal age are well established for mothers and their children, and include heightened risk of pre-term labor, fetal growth restriction, and fetal demise among those over 35, in comparison to younger mothers (Sauer 2015). ${ }^{17}$ Pregnancy when young also tends to be associated with risk, but often for social as well as biological reasons. To capture non-linear age effects, we include continuous controls for maternal age and the square of maternal age. We adjust for sex of the child (0 if male, 1 if female) and parity (with a set of binary dummy variables). We also include controls for conception year by month fixed effects to control for seasonal effects and any time trend ${ }^{18}$, as well as day of the week at birth fixed effects (He et al. 2016). Finally, we adjust for daily mean rainfall during the duration of pregnancy using a cubic function of daily mean rainfall in all regressions to model the nonlinear relationship between rainfall and birth weight. ${ }^{19}$

\subsection{Analytic Approach}

We model birth weight as related to maternal education, air pollution and extreme temperature exposure in both mean and quantile regression frameworks. We first estimate a baseline main

${ }^{16}$ Calculated from National Bureau of Statistics of China (2021).

${ }^{17}$ We have found few studies that identify whether advanced maternal age places mothers at particular risk to conditions of air pollution exposure. However, one cohort study in Wuxi, China showed an effect modification with maternal age: preterm birth risk associated with exposure to high levels of $\mathrm{PM}_{10}$ occurred primarily among women over age 35 (Han et al. 2018).

${ }^{18}$ Controlling for seasonal trends is a common specification in studying the health impacts of ambient environment. Depending on the structure of the data, the literature uses different ways of controlling, varying from calendar day in a year trends (Chen et al. 2020), to year-by-month fixed effects to exploit within-calendar month variation in the ambient environment (Janke 2014), to year and month fixed effects to exploit cross-year variation in ambient environment in the same month (Currie and Rossin-Slater 2013). To exploit the daily variation in air pollution level, we choose to include year-by-month fixed effects to control for seasonal effects and changes in economic conditions over time that are shared commonly across the city that may also confound the results.

${ }^{19}$ Rainfall has been related to birth outcomes in a number of studies (Currie and Rossin-Slater 2013; Rocha and Soares 2015). Given this precedent and the monsoon climate in Guangzhou, which is often exposed to typhoons, we control for rainfall in our study. Relative humidity is also a common confounder for birth outcomes (He et al. 2016; Rich et al. 2015). However, since our temperature variable, UTCI, by construction, has already incorporated both dry bulb temperature and relative humidity, we do not include relative humidity as a separate control in our analysis. Nevertheless, our results are robust if we drop rainfall and include relative humidity in regressions. 
effects (conditional) mean regression model:

$$
\begin{aligned}
\text { BirthWeight }_{\mathrm{ymi}}= & \alpha+\zeta_{\mathrm{ym}}+\sigma_{0} \mathrm{Edu}_{i} \\
& +\gamma_{1} P_{i}+\gamma_{2} \operatorname{Cold}_{i}+\gamma_{3} \text { Heat }_{i} \\
& +g\left(\operatorname{Rainfall}_{i}\right)+\mathbf{X}_{i} \theta^{\prime}+\varepsilon_{i},
\end{aligned}
$$

where BirthWeight $_{\mathrm{ymi}}$ is birth weight of individual $i$ who is conceived in year $y$ and month $m$. $\mathrm{Edu}_{i}$ is a binary variable indicating if a mother has at least a college degree. $P_{i}$ is a continuous variable measuring each mother's prenatal ambient exposure to $\mathrm{PM}_{10}$, or the composite index of $\mathrm{PM}_{10}, \mathrm{NO}_{2}$ and $\mathrm{SO}_{2}$. Cold $i$, and $\mathrm{Heat}_{i}$ are continuous variables measuring the percentages of prenatal days exposed to extreme cold or heat. $g$ (Rainfall $\left.l_{i}\right)$ is a cubic function of daily mean precipitation that a mother is exposed to during her pregnancy. We control for an individualspecific vector of attributes $X_{i}$, which includes linear and quadratic terms for maternal age, child's sex, parity, number of multiple births, and birth day of the week. To control for shifts in seasonal patterns of birth as well as possible changes in economic conditions over time, we include conception year and month interaction fixed effects $\zeta_{y m} \cdot{ }^{20}$ Given these, Equation (1) compares the birth weights of infants conceived in the same calendar month and examines the associations of cumulative within-month variation in air pollution and temperature with variation of birth weights.

Equation (1) restricts the birth weight gradient with college education to be constant, which is captured by $\sigma_{0}$ and is invariant of ambient environmental exposures. Equation (2) relaxes this restriction, and allows the birth-weight gradient with college education to potentially vary

\footnotetext{
${ }^{20}$ Due to significant day-to-day variations in pollution exposures as shown in Figure 1 and Figure 3 , despite the inclusion of year and month interaction fixed effects, there remains sufficient variations in pollution exposures that allow for identification. These variations, in effect, arise due to day-by-day differences in exposures in the first and last months of pregnancy. In our regression framework, we assume homogeneous effects of pollution exposures during the course of pregnancy.
} 
depending on $P_{i}$, Cold $i$, and Heat ${ }_{i}$ :

$$
\begin{aligned}
\text { birth weight }_{\mathrm{ymi}}= & \alpha+\zeta_{y m}+\sigma_{0} \mathrm{Edu}_{i} \\
& +\gamma_{1} P_{i}+\gamma_{2} \operatorname{Cold}_{i}+\gamma_{3} \mathrm{Heat}_{i} \\
& +\sigma_{1} \mathrm{Edu}_{i} \times P_{i}+\sigma_{2} \mathrm{Edu}_{i} \times \operatorname{Cold}_{i}+\sigma_{3} \mathrm{Edu}_{i} \times \mathrm{Heat}_{i} \\
& +g\left(\text { Rainfall }_{i}\right)+\mathbf{X}_{i} \theta^{\prime}+\varepsilon_{i},
\end{aligned}
$$

where positive values for $\sigma_{1}, \sigma_{2}$ and $\sigma_{3}$ combined with negative values for $\gamma_{1}, \gamma_{2}$ and $\gamma_{3}$ would imply protective effects of maternal college education that ameliorate the negative impacts of ambient air pollution, extreme cold, and extreme heat on birth weight.

We estimate Equations (1) and (2) both via conditional mean (OLS) and conditional quantile estimation. $^{21}$ Under OLS, Equation (2) imposes the restriction that the birth weight-college education gradient — conditional on observed variables including the vector of environmental exposure measures $P_{i}, \mathrm{Cold}_{i}$, and Heat ${ }_{i}$-is constant across individuals. The implicit assumption is that the birth weight-college education gradient is invariant across the conditional distribution of birth weight, where the conditional distribution captures unobserved factors-including nutrition, avoidance behavior, genetic factors, or other risk factors - that can also impact birth weight. However, given the same ambient environment, the tendency for college-educated mothers to have babies with higher birth weight compared to non-college-educated mothers may be most pronounced at the lower conditional quantiles of unobserved innate vulnerabilities. Additionally, babies with greater unobserved innate vulnerabilities might be more likely to suffer from air pollution and extreme temperatures.

Our conditional quantile analysis allows birth weight-college education gradients to vary both along observed dimensions of sources of vulnerabilities, i.e., potential negative environmental factors (as seen in the interaction effects in Equation (2)), and along unobserved dimensions

\footnotetext{
${ }^{21}$ Under OLS, the same estimated coefficients provide both conditional and unconditional mean predictions; under quantile estimations, conditional quantile estimates in general can differ from unconditional quantile results (Firpo, Fortin, and Lemieux 2009). In this paper, we use conditional quantile estimates to study heterogeneous maternal education and birth weight gradients on levels (grams) of birth weight. While Firpo, Fortin, and Lemieux (2009) show that in the context of birth weight, conditional and unconditional quantile estimates can be similar, we do not consider the implications of our estimates for the unconditional (marginal) distribution of birth weight. We estimate quantile regressions with the quantreg package (Koenker 2020).
} 
of sources of baby vulnerabilities, as captured by different conditional quantiles. The results provide a finer disentangling of heterogeneities of the birth weight-maternal education gradients. For example, the conditional mean estimates could understate the importance of $\mathrm{PM}_{10}$ if the negative relationship between $\mathrm{PM}_{10}$ and birth weight is magnified at lower conditional quantiles where mothers/children have greater unobserved innate vulnerabilities.

\section{Results}

\subsection{Mean Regression Results}

Results from mean regressions with $\mathrm{PM}_{10}$ as the only air pollutant are presented in Table 3. Columns 1 and 3 show the Equation (1) estimates. Columns 2 and 4 show the Equation (2) estimates, which include interaction terms between maternal education and environmental exposure variables. In columns 1 and 2, extreme temperature is defined by $1 \%$ extreme tails of past temperatures, while columns 3 and 4 use $2.5 \%$ as the tail cutoffs.

After controlling for conception year-by-month fixed effects, $\mathrm{PM}_{10}$, extreme cold, and extreme heat are all negatively and substantially associated with birth weight. Column 1 in Table 3 shows that a $1 \mu \mathrm{g} / \mathrm{m}^{3}$ increase in average daily $\mathrm{PM}_{10}$ potential exposure during pregnancy is associated with an 17.8 gram reduction of birth weight (s.e. 2.3). An additional percentage point increase in potential exposure to extreme heat or cold is associated with a 22.4 gram (s.e. 9.4) or 30.8 gram (s.e. 9.8) birth weight reduction, respectively. Stated differently, a one standard deviation change in potential exposure to $\mathrm{PM}_{10}$ (i.e., $6.6 \mu \mathrm{g} / \mathrm{m}^{3}$ ), extreme heat (i.e., $1.61 \%$ of pregnant days), or extreme cold (i.e., $1.00 \%$ of pregnant days) corresponds to $0.25,0.08$, and 0.07 standard deviation changes in birth weights, respectively. ${ }^{22}$ The results from Columns 1 and 3 are similar. The exception is that in Column 3, with the less-extreme temperature thresholds, heat exposure is no longer significantly negatively associated with birth weight.

\footnotetext{
${ }^{22}$ While the magnitudes of the associations between $\mathrm{PM}_{10}$ or other pollutants and birth weights in relatively low pollution settings are generally smaller than what we find, our results are similar to the findings obtained by Bharadwaj and Eberhard (2008) from Chile - a setting with similar mean $\mathrm{PM}_{10}$ exposures as our setting herewhere results show that a one standard deviation $\left(17 \mu \mathrm{g} / \mathrm{m}^{3}\right)$ increase in $\mathrm{PM}_{10}$ exposures is associated with 0.23 standard deviations (125 grams) of birth-weight reduction.
} 
Columns 2 and 4 show the maternal college education interaction coefficient estimates. ${ }^{23}$ In both columns, mothers' college education status is associated with reduced vulnerability to ambient air pollution and extreme heat exposures. However, this protective effect of mothers' college is not significant for extreme cold. Focusing on Column 2, there is a positive collegeeducation interaction coefficient of 2.0 (s.e. 0.7) for $\mathrm{PM}_{10}$ and 11.8 (s.e. 2.9) for extreme heat. Comparing college-educated to non-college-educated mothers, the interactions correspond to a $10 \%$ dampening of the negative association of $\mathrm{PM}_{10}$ with birth weight and a $44 \%$ dampening of the negative association of extreme heat with birth weight.

We evaluate the college premium in birth weight, which we define to be the predicted gap in birth weight between college-educated and non-college-educated mothers, by considering the negative intercept for college education, -115.7 (s.e. 53.2), and the positive education slopes jointly. Holding extreme heat and cold exposures at their respective means, the college premium amounts to $0.05,0.08$, and 0.16 standard deviations of birth weight at the $1^{\text {st }}\left(63 \mu \mathrm{g} / \mathrm{m}^{3}\right), 50^{\text {th }}$ (70 $\left.\mu \mathrm{g} / \mathrm{m}^{3}\right)$, and $99^{\text {th }}\left(89 \mu \mathrm{g} / \mathrm{m}^{3}\right)$ percentiles of the marginal distribution of $\mathrm{PM}_{10}$. Similarly, holding $\mathrm{PM}_{10}$ and extreme cold at their respective means, the college premium amounts to 0.05 , 0.07 and 0.17 standard deviations of birth weight at the $1^{\text {st }}(0 \%), 50^{\text {th }}(0.76 \%)$ and $99^{\text {th }}(4.71 \%)$ percentiles of the marginal distribution of the percentage of pregnancy days exposed to extreme heat.

\subsection{Quantile Regression Results}

Conditional quantile results, without and with maternal education interactions with the three environmental measures, are shown in Tables 4 and 5, respectively. These estimates use the more stringent cold and heat exposure measures defined by the $1 \%$ cutoffs. Because these are conditional quantile estimates, the quantiles are defined with respect to what we call the children's unobserved innate vulnerabilities (i.e., the residuals in the birth weight regressions, not the birth weights themselves).

\footnotetext{
23 The coefficient estimates for college education appear negative in the interaction specifications (columns 2 and 4). In these specifications, college education coefficients represent intercepts (adjusting for other variables in the model) for the hypothetical situation of no $\mathrm{PM}_{10}$, cold, or heat exposure. The predicted protective effects of maternal education given the observed range of ambient environmental measures are presented in our discussion of college premiums for birth weights.
} 


\subsubsection{Baseline Quantile Regression Results}

Table 4 shows a negative gradient for college education over ascending conditional quantile estimates, indicating that the protective effects of college education on birth weight decrease as we move from the left to the right tail of the conditional distribution of birth weight. Specifically, the coefficient estimates on mothers' college completion status are 64.6 (s.e. 8.1), 21.8 (s.e. 4.8), and 11.2 (s.e. 7.4 ) at the $10^{\text {th }}, 50^{\text {th }}$, and $90^{\text {th }}$ conditional quantiles. These amount to $0.14,0.05$, and 0.02 standard deviations of birth weight.

Additionally, the negative associations between the three environmental measures and birth weight are all stronger at lower conditional quantiles. The $\mathrm{PM}_{10}$ coefficients at the $10^{\text {th }}, 50^{\text {th }}$, and $90^{\text {th }}$ conditional quantiles are -38.9 (s.e. 3.5), -22.2 (s.e. 2.1), and -17.5 (s.e. 2.8). A one standard deviation increase in potential $\mathrm{PM}_{10}$ exposures is associated with $0.55,0.31$, and 0.25 standard deviation reductions of birth weight, respectively. For extreme heat and cold, respectively, the magnitudes of the negative associations are 2.4 and 3.7 times larger at the $10^{\text {th }}$ conditional quantile versus the $90 .^{\text {th }}$ At the $10^{\text {th }}$ conditional quantiles, a one standard deviation increase in extreme heat or cold is associated with a 0.06 or 0.13 standard deviation reduction of birth weights, respectively.

Table 4 also indicates increasing estimates for males, decreasing estimates for mother's age, as well as increasing estimates for mother's age squared along ascending conditional quantiles estimates. The directions and magnitudes of these coefficient estimates are similar to those reported in the existing research on conditional and unconditional quantile estimates for birth weights (Abrevaya 2001; Firpo, Fortin, and Lemieux 2009; Koenker and Hallock 2001).

\subsubsection{Quantile Regression Results with Interactions}

At lower conditional quantiles, maternal college education ameliorates the negative associations between birth weight and pollution and extreme heat, but not extreme cold. As shown in Table 5 and Figure 4, the college-education interaction coefficient estimates for $\mathrm{PM}_{10}$ are 5.7 (s.e. 1.3), 1.3 (s.e. 0.7), and 0.0 (s.e. 1.1) at the $10^{\text {th }}, 50^{\text {th }}$, and $90^{\text {th }}$ conditional quantiles. These respectively correspond to 14,6 , and $0 \%$ reductions in the substantial negative associations between $\mathrm{PM}_{10}$ and birth weight compared to non-college-educated mothers. Additionally, the 
college-education interaction coefficient estimates for extreme heat are 26.4 (s.e. 5.4), 7.3 (s.e. 3.3), and 6.2 (s.e. 4.8) at the $10^{\text {th }}, 50^{\text {th }}$, and $90^{\text {th }}$ conditional quantiles. While the overall associations of extreme heat with birth weights are less substantial than the associations of $\mathrm{PM}_{10}$ with birth weights, these coefficients, respectively, correspond to 71,31 , and $47 \%$ reductions in the associations between extreme heat and birth weight.

Considering jointly the positive slopes and negative intercepts from Table 5, the college premium in birth weight is magnified at lower conditional quantiles. Holding heat and cold exposure variables at their means, the college premiums at the $1^{\text {st }}, 50^{\text {th }}$ and $99^{\text {th }}$ percentiles of the marginal distribution of $\mathrm{PM}_{10}$ amount to $0.02,0.02$, and 0.02 standard deviations of birth weight with $90^{\text {th }}$ conditional quantile estimates, and are magnified substantially to $0.03,0.11$, and 0.34 standard deviations of birth weight with $10^{\text {th }}$ conditional quantile estimates. These results are visualized in Figure 5. Additionally, holding $\mathrm{PM}_{10}$ and cold exposures at their means, the college premiums at the $1^{\text {st }}, 50^{\text {th }}$ and $99^{\text {th }}$ percentiles of the marginal distribution of extreme heat amount to $0.00,0.01$, and 0.06 standard deviations of birth weight with the $90^{\text {th }}$ conditional quantile estimates, and are magnified to $0.06,0.10$, and 0.32 standard deviations with the $10^{\text {th }}$ conditional quantile estimates. In contrast, the associations between extreme cold exposures and birth weights do not vary across maternal education groups, so there are no significant variations in the college premium in birth weight as extreme cold exposures increase.

\subsection{Composite Index Analysis}

We repeat the analyses parallel to that for $\mathrm{PM}_{10}$ but with the composite index pollution measure. Detailed results are presented in Appendix Tables A.1, A.2, and A.3. Patterns in the temperature results are robust to the choice of pollution measure, and are not discussed here. The results from the composite index analysis closely mirror the patterns revealed in the $\mathrm{PM}_{10}$ analysis. There is a protective effect of maternal education with regard to pollution, and the finding persists across conditional quantiles of birth weight. Further, quantile regressions show that the negative associations between pollution and birth weight, and the protective effects of maternal education with respect to pollution, are magnified at lower conditional quantiles.

A key difference in the composite index analysis results is that for estimates based on 
Equation (1) without maternal education interactions, the birth weight change associated with one standard deviation change in the composite index is 1.8 times of the corresponding change in the $\mathrm{PM}_{10}$ analysis. In the regressions with interactions, the protective effect of college education is weaker in the composite index analysis than in the $\mathrm{PM}_{10}$ analysis. Together, these factors lead to a pattern in which the college premium in grams of birth weight along the marginal distribution of the composite index is approximately the same as the college premium in birth weight along the marginal distribution of $\mathrm{PM}_{10}$.

\subsection{Summary}

Conditional on ambient temperature exposures, we find that one standard deviation increase in ambient $\mathrm{PM}_{10}$ is associated with a 0.25 standard deviation reduction in birth weight. At average ambient $\mathrm{PM}_{10}$ and extreme temperature exposure levels, the protective effect of maternal college education is up to 0.07 standard deviations of birth weight. We also find that the negative association between ambient exposures and birth weight is two times as large at lower conditional quantiles of birth weight than at the median. At lower conditional quantiles of birth weight, a one standard deviation increase in ambient $\mathrm{PM}_{10}$ exposure is associated with a reduction in birth weight of up to 0.48 standard deviations.

Additionally, the protection associated with university-educated mothers with respect to pollution and extreme heat is five times as large at the lowest decile of conditional quantiles of birth weight than at the highest decile. In particular, the protective effect of college education can be up to 0.34 standard deviations of birth weight when children with higher unobserved innate vulnerabilities - those at lower conditional quantiles - face high levels of ambient $\mathrm{PM}_{10}$ and extreme temperature exposures. Though we focus on a continuous measure of birth weight for all terms in the text, we find similar results with binary measures used in some other studies for low birth weight, preterm births, and small for gestational age (Appendix Section A.4). Our results show that there are substantively significant heterogeneous moderating effects of maternal education on the negative associations between ambient environmental exposures and birth weight. We are the first to document these relationships using mean and conditional quantile regressions with an approach in which we consider three key ambient environmental 
exposures jointly.

\section{Discussion and Conclusion}

In this paper, we link a database of all births recorded for three years born in hospitals in a district in Guangzhou, China, to daily measures of particulate matter $\left(\mathrm{PM}_{10}\right)$, nitrogen dioxide, and sulfur dioxide and to daily meteorological measurements during pregnancies. Using conditional mean and quantile regressions, we estimate the associations of birth weight with air pollution, measured by ambient $\mathrm{PM}_{10}$ and a composite pollution measure, and with extreme cold and hot temperatures. To our knowledge, this paper is the first study of birth outcomes in a fairly high-pollution context to consider effect modifications of both pollution and extreme weather by maternal education. It is also novel in addressing whether the protective effects of maternal education are heterogeneous with respect to babies' unobserved innate vulnerabilities.

Our approach has certain limitations. First, we cannot observe mothers' addresses, which would have enabled us to match to the air pollution level from the closest monitoring station. On the other hand, our approach of using core city districts' pollution levels is reasonable if we assume that women who give birth in a district are likely to live and move around primarily in that district and neighboring districts. We are encouraged that our results are not sensitive to our choice of a proxy for ambient exposure: results are robust to whether we use city-wide pollution measures or center-city district pollution measures (Appendix Section A.2).

A second limitation of the paper is that it is geographically limited to one locale. Under the assumption of homogeneous environmental effects across locations, more cities would be beneficial in terms of additional variance in environmental and temperature exposure variables and would improve the precision of estimates. However, if effects are heterogeneous across locations, an average effect obtained from information over multiple locations might not properly capture varying local effects. Accounting for differences across locations appropriately is potentially especially important for temperature effects, which are a focus in our paper. Relative temperature matters - the implications for pregnancy of a given temperature may differ across 
temperature zones. Focusing on a single region has the advantage of avoiding this problem. ${ }^{24}$ The experience of Guangzhou may not generalize across China, but it offers a case study that is potentially relevant to other urban settings in south China, and possibly parts of Southeast Asia, characterized by broadly similar climates, high levels of pollution, and economic conditions. Finally, the administrative data to which we have access has excellent measurement of birth outcomes, relative to self-reported survey data. However, it contains very limited information about mothers. This limitation precludes analysis of other dimensions of socioeconomic status beyond maternal education or behavioral mechanisms that might explain the patterns we find.

With these caveats in mind, we find strong negative associations between ambient $\mathrm{PM}_{10}$ and extreme temperature exposures and birth weights. For example, a one standard deviation increase in $\mathrm{PM}_{10}$ exposure-6.6 $\mu \mathrm{g} / \mathrm{m}^{3}$-is associated with a 116 to 258 gram reduction in birth weights. One standard deviation—on average, 2.7 days-increase in prenatal exposure to extreme cold temperatures (lower than -0.87 degrees Celsius in universal thermal climate indices) is associated with a 17 to 63 gram reduction in birth weights. One standard deviationon average, 4.3 days-increase in prenatal exposure to extreme hot temperatures (higher than 34.23 degrees Celsius, in universal thermal climate indices) is associated with a 12 to 31 gram reduction in birth weights. Stronger associations are seen for children with greater levels of unobserved innate vulnerabilities at lower conditional quantiles.

There is also strong evidence for effect modification with maternal education. Newborns of mothers with college attainment experience an amelioration of effects on birth weight of $\mathrm{PM}_{10}$ by about 0 to $14 \%$, and of extreme hot weather by 31 to $70 \%$, with larger buffering effects experienced by those at lower conditional quantiles. However, there is no effect modification with maternal education in response to extreme cold weather. This result is understandable in a context in which centralized heating is not widely available. Although there is usually only a short spell of very cold weather in each year, our results indicate that even a few days of very cold weather exposure is associated with lower birth weights. Given the lack of indoor heating, even

\footnotetext{
${ }^{24}$ Our paper capitalizes on full administrative data, rather than sample data from one location. For a study that is focused on distributional outcomes, it is important to capture the full range of birth weight distributions and we are able to do this. There are benefits to having more people in the same location, which allows for careful control of location-specific time-trends that could vary with changes in local economic conditions that might correlate with birth weight.
} 
mothers with higher socioeconomic status might have no effective way of protecting themselves from exposure to extreme cold weather. In contrast, air conditioning was widely available during the time period of this study and was very accessible for higher socioeconomic status mothers.

In short, our findings demonstrate that babies of college-educated mothers-compared to babies of other mothers in the same district of Guangzhou—experienced lower risk in the context of air pollution and extreme heat exposure. It is important to note that the benefits accruing to babies of college-educated mothers vary. The protective effects are most pronounced among those experiencing more environmental risk-more extreme ambient pollution and heat exposure. Protective effects of maternal education also emerge more strongly for infants with greater unobserved innate vulnerabilities. In other words, socioeconomic disparities and underlying child health vulnerabilities both stratify the realized impacts associated with a common ambient environment-especially when that common ambient environment is extreme pollution or extreme hot temperatures. Our findings suggest that babies at greatest risk from high pollution levels and increasingly frequent heat events are those at the nexus of socioeconomic and health vulnerability. 


\section{References}

Abel, Ernest L., Michael Kruger, and Larry Burd. 2002. "Effects of Maternal and Paternal Age on Caucasian and Native American Preterm Births and Birth Weights." American Journal of Perinatology 19 (01): 049-054. https://doi.org/10.1055/s-2002-20173.

Abrevaya, Jason. 2001. "The Effects of Demographics and Maternal Behavior on the Distribution of Birth Outcomes.” Empirical Economics 26, no. 1 (March): 247-257. https://doi.org/10. 1007/s001810000052.

Abrevaya, Jason, and Christian M Dahl. 2008. "The Effects of Birth Inputs on Birthweight: Evidence From Quantile Estimation on Panel Data." Journal of Business \& Economic Statistics 26, no. 4 (October): 379-397. https://doi.org/10.1198/073500107000000269.

Arias, Omar, Kevin F. Hallock, and Walter Sosa-Escudero. 2001. "Individual Heterogeneity in the Returns to Schooling: Instrumental Variables Quantile Regression Using Twins Data." Empirical Economics 26, no. 1 (March): 7-40. https://doi.org/10.1007/s001810000053.

Ballon, Morgane, Jérémie Botton, Anne Forhan, Blandine Lauzon-Guillain, Maria Melchior, Fabienne El Khoury, Aurélie Nakamura, et al. 2019. "Which Modifiable Prenatal Factors Mediate the Relation Between Socio-economic Position and a Child's Weight and Length at Birth?" Maternal and Child Nutrition 15, no. 4 (October). https://doi.org/10.1111/mcn. 12878 .

Basu, Rupa, Reina Rau, Dharshani Pearson, and Brian Malig. 2018. "Temperature and Term Low Birth Weight in California.” American Journal of Epidemiology 187, no. 11 (November): 2306-2314. https://doi.org/10.1093/aje/kwy116.

Behrman, Jere R., and Mark R. Rosenzweig. 2004. "Returns to Birthweight." Review of Economics and Statistics 86, no. 2 (May): 586-601. https://doi.org/10.1162/003465304323031 139.

Behrman, Jere R., Yanyan Xiong, and Junsen Zhang. 2015. "Cross-Sectional Schooling-Health Associations Misrepresented Causal Schooling Effects on Adult Health and Health-Related Behaviors: Evidence from the Chinese Adults Twins Survey." Social Science \& Medicine 127 (February): 190-197. https://doi.org/10.1016/j.socscimed.2014.11.011.

Bekkar, Bruce, Susan Pacheco, Rupa Basu, and Nathaniel DeNicola. 2020. "Association of Air Pollution and Heat Exposure With Preterm Birth, Low Birth Weight, and Stillbirth in the US: A Systematic Review." JAMA Network Open 3, no. 6 (June): e208243. https: //doi.org/10.1001/jamanetworkopen.2020.8243.

Bharadwaj, Prashant, and Juan Eberhard. 2008. "Atmospheric Air Pollution and Birth Weight." SSRN Electronic Journal, https://doi.org/10.2139/ssrn.1197443.

Black, Sandra E., Paul J. Devereux, and Kjell G. Salvanes. 2007. "From the Cradle to the Labor Market? The Effect of Birth Weight on Adult Outcomes*." The Quarterly Journal of Economics 122, no. 1 (February): 409-439. https://doi.org/10.1162/qjec.122.1.409.

Bröde, Peter, Dusan Fiala, Krzysztof Błażejczyk, Ingvar Holmér, Gerd Jendritzky, Bernhard Kampmann, Birger Tinz, et al. 2012. "Deriving the Operational Procedure for the Universal Thermal Climate Index (UTCI).” International Journal of Biometeorology 56, no. 3 (May): 481-494. https://doi.org/10.1007/s00484-011-0454-1.

Buchholz, Katharina. 2019. Infographic: The Explosive Growth of Chinese Cities. Statista, August. http://www.statista.com/chart/19189/gdp-growth-in-chinese-cities/. 
Chen, Gongbo, Yuming Guo, Michael J. Abramson, Gail Williams, and Shanshan Li. 2018. "Exposure to Low Concentrations of Air Pollutants and Adverse Birth Outcomes in Brisbane, Australia, 2003-2013." Science of The Total Environment 622-623 (May): 721-726. https: //doi.org/10.1016/j.scitotenv.2017.12.050.

Chen, Jinjian, Hang Dong, Jun Yang, Li Li, Jieqi Jin, Zhou Yang, Guozhen Lin, et al. 2021. "The Impact of Cold Spells on Mortality from a Wide Spectrum of Diseases in Guangzhou, China." Environmental Research Letters 16, no. 1 (January): 015009. https://doi.org/10. 1088/1748-9326/abd26f.

Chen, Siyu, Chongshan Guo, and Xinfei Huang. 2018. "Air Pollution, Student Health, and School Absences: Evidence from China." Journal of Environmental Economics and Management 92 (November): 465-497. https://doi.org/10.1016/j.jeem.2018.10.002.

Chen, Xi, Chih Ming Tan, Xiaobo Zhang, and Xin Zhang. 2020. "The Effects of Prenatal Exposure to Temperature Extremes on Birth Outcomes: The Case of China." Journal of Population Economics (March). https://doi.org/10.1007/s00148-020-00768-4.

Chen, Le-Yu, and Christine Ho. 2016. "Incense Burning During Pregnancy and Birth Weight and Head Circumference Among Term Births: The Taiwan Birth Cohort Study." Environmental Health Perspectives 124, no. 9 (September): 1487-1492. https://doi.org/10.1289/ehp. 1509922.

Cho, Hyunkuk. 2020. "Ambient Temperature, Birth Rate, and Birth Outcomes: Evidence from South Korea.” Population and Environment 41, no. 3 (March): 330-346. https://doi.org/10. 1007/s11111-019-00333-6.

Climate-Data.org. 2020. Guangzhou Climate: Average Temperature, Weather by Month. Data. https://en.climate-data.org/asia/china/guangdong/guangzhou-2309/.

Copernicus and European Centre for Medium-Range Weather Forecasts. 2020. Universal Thermal Climate Index. Climate Data. https://urbansis.eu/universal-thermal-climate-index/.

Currie, Janet. 2013. "Pollution and Infant Health." Child Development Perspectives 7, no. 4 (December): 237-242. https://doi.org/10.1111/cdep.12047.

Currie, Janet, and Maya Rossin-Slater. 2013. "Weathering the Storm: Hurricanes and Birth Outcomes.” Journal of Health Economics 32, no. 3 (May): 487-503. https://doi.org/10. 1016/j.jhealeco.2013.01.004.

Currie, Janet, and Reed Walker. 2011. "Traffic Congestion and Infant Health: Evidence from EZPass.” American Economic Journal: Applied Economics 3, no. 1 (January): 65-90. https: //doi.org/10.1257/app.3.1.65.

Currie, Janet, Joshua Graff Zivin, Jamie Mullins, and Matthew Neidell. 2014. "What Do We Know About Short-and Long-Term Effects of Early-Life Exposure to Pollution?" Annual Review of Resource Economics 6 (1): 217-247. https://doi.org/10.1146/annurev-resource100913-012610.

Darrow, Lyndsey A., Mitchel Klein, W Dana Flanders, Lance A. Waller, Adolfo Correa, Michele Marcus, James A. Mulholland, et al. 2009. "Ambient Air Pollution and Preterm Birth: A Time-Series Analysis.” Epidemiology 20, no. 5 (September): 689-698. https://doi.org/10. 1097/EDE.0b013e3181a7128f.

DeCicca, Philip, and Natalie Malak. 2020. "When Good Fences Aren't Enough: The Impact of Neighboring Air Pollution on Infant Health.” Journal of Environmental Economics and Management 102 (July): 102324. https://doi.org/10.1016/j.jeem.2020.102324. 
Deschênes, Olivier. 2014. "Temperature, Human Health, and Adaptation: A Review of the Empirical Literature.” Energy Economics 46 (November): 606-619. https://doi.org/10. 1016/j.eneco.2013.10.013.

Deschênes, Olivier, Michael Greenstone, and Jonathan Guryan. 2009. "Climate Change and Birth Weight." American Economic Review 99, no. 2 (April): 211-217. https://doi.org/10. 1257/aer.99.2.211.

Ebisu, Keita, Jesse D. Berman, and Michelle L. Bell. 2016. "Exposure to Coarse Particulate Matter During Gestation and Birth Weight in the U.S." Environment International 94 (September): 519-524. https://doi.org/10.1016/j.envint.2016.06.011.

Firpo, Sergio, Nicole M. Fortin, and Thomas Lemieux. 2009. "Unconditional Quantile Regressions." Econometrica 77 (3): 953-973. https://doi.org/10.3982/ECTA6822.

Fleischer, Nancy L., Mario Merialdi, Aaron van Donkelaar, Felipe Vadillo-Ortega, Randall V. Martin, Ana Pilar Betran, João Paulo Souza, et al. 2014. "Outdoor Air Pollution, Preterm Birth, and Low Birth Weight: Analysis of the World Health Organization Global Survey on Maternal and Perinatal Health.” Environmental Health Perspectives 122, no. 4 (April): 425-430. https://doi.org/10.1289/ehp.1306837.

Fong, Kelvin C., Anna Kosheleva, Itai Kloog, Petros Koutrakis, Francine Laden, Brent A. Coull, and Joel D. Schwartz. 2019. "Fine Particulate Air Pollution and Birthweight: Differences in Associations Along the Birthweight Distribution.” Epidemiology 30, no. 5 (September): 617-623. https://doi.org/10.1097/EDE.0000000000001039.

Grady, Sue C. 2006. "Racial Disparities in Low Birthweight and the Contribution of Residential Segregation: A Multilevel Analysis." Social Science \& Medicine 63, no. 12 (December): 3013-3029. https://doi.org/10.1016/j.socscimed.2006.08.017.

Ha, Sandie, Yeyi Zhu, Danping Liu, Seth Sherman, and Pauline Mendola. 2017. “Ambient Temperature and Air Quality in Relation to Small for Gestational Age and Term Low Birthweight." Environmental Research 155 (May): 394-400. https://doi.org/10.1016/j. envres.2017.02.021.

Han, Yingying, Panhua Jiang, Tianyu Dong, Xinliang Ding, Ting Chen, Gro Dehli Villanger, Heidi Aase, et al. 2018. "Maternal Air Pollution Exposure and Preterm Birth in Wuxi, China: Effect Modification by Maternal Age." Ecotoxicology and Environmental Safety 157 (August): 457-462. https://doi.org/10.1016/j.ecoenv.2018.04.002.

Hanandita, Wulung, and Gindo Tampubolon. 2015. "The Double Burden of Malnutrition in Indonesia: Social Determinants and Geographical Variations." SSM - Population Health 1 (December): 16-25. https://doi.org/10.1016/j.ssmph.2015.10.002.

Hansen, C., A. Neller, G. Williams, and R. Simpson. 2006. "Maternal Exposure to Low Levels of Ambient Air Pollution and Preterm Birth in Brisbane, Australia." BJOG: An International Journal of Obstetrics \& Gynaecology 113 (8): 935-941. https://doi.org/https://doi.org/10. 1111/j.1471-0528.2006.01010.x.

Hao, Hua, Howard H. Chang, Heather A. Holmes, James A. Mulholland, Mitch Klein, Lyndsey A. Darrow, and Matthew J. Strickland. 2016. "Air Pollution and Preterm Birth in the U.S. State of Georgia (2002-2006): Associations with Concentrations of 11 Ambient Air Pollutants Estimated by Combining Community Multiscale Air Quality Model (CMAQ) Simulations with Stationary Monitor Measurements." Environmental Health Perspectives 124, no. 6 (June): 875-880. https://doi.org/10.1289/ehp.1409651.

He, Jian-Rong, Yu Liu, Xiao-Yan Xia, Wen-Jun Ma, Hua-Liang Lin, Hai-Dong Kan, Jin-Hua Lu, et al. 2016. "Ambient Temperature and the Risk of Preterm Birth in Guangzhou, China 
(2001-2011)." Environmental Health Perspectives 124 (7): 1100-1106. https://doi.org/10. 1289/ehp.1509778.

He, Jiaxiu, Haoming Liu, and Alberto Salvo. 2019. "Severe Air Pollution and Labor Productivity: Evidence from Industrial Towns in China." American Economic Journal: Applied Economics 11, no. 1 (January): 173-201. https://doi.org/10.1257/app.20170286.

Heo, Seulkee, Kelvin C Fong, and Michelle L Bell. 2019. "Risk of Particulate Matter on Birth Outcomes in Relation to Maternal Socio-Economic Factors: A Systematic Review." Environmental Research Letters 14, no. 12 (November): 123004. https://doi.org/10.1088/ 1748-9326/ab4cd0.

Hooven, Edith H. van den, Frank H. Pierik, Yvonne de Kluizenaar, Sten P. Willemsen, Albert Hofman, Sjoerd W. van Ratingen, Peter Y.J. Zandveld, et al. 2012. "Air Pollution Exposure During Pregnancy, Ultrasound Measures of Fetal Growth, and Adverse Birth Outcomes: A Prospective Cohort Study.” Environmental Health Perspectives 120, no. 1 (January): 150 156. https://doi.org/10.1289/ehp.1003316.

Hu, Zihan, and Teng Li. 2019. "Too Hot to Handle: The Effects of High Temperatures During Pregnancy on Adult Welfare Outcomes." Journal of Environmental Economics and Management 94 (March): 236-253. https://doi.org/10.1016/j.jeem.2019.01.006.

Huang, Ching-chun, Shih-chun Pan, Bing-yu Chen, and Yue Leon Guo. 2020. "Periconceptional Exposure to Air Pollution and Congenital Hypospadias Among Full-Term Infants." Environmental Research 183 (April): 109151. https://doi.org/10.1016/j.envres.2020.109151.

Ito, Koichiro, and Shuang Zhang. 2020. "Willingness to Pay for Clean Air: Evidence from Air Purifier Markets in China." Journal of Political Economy 128, no. 5 (May): 1627-1672. https://doi.org/10.1086/705554.

Jacobs, Milena, Guicheng Zhang, Shu Chen, Ben Mullins, Michelle Bell, Lan Jin, Yuming Guo, et al. 2017. "The Association Between Ambient Air Pollution and Selected Adverse Pregnancy Outcomes in China: A Systematic Review." Science of The Total Environment 579 (February): 1179-1192. https://doi.org/10.1016/j.scitotenv.2016.11.100.

Janke, Katharina. 2014. "Air Pollution, Avoidance Behaviour and Children's Respiratory Health: Evidence from England." Journal of Health Economics 38 (December): 23-42. https://doi. org/10.1016/j.jhealeco.2014.07.002.

Jiang, Li-Li, Yun-Hui Zhang, Gui-Xiang Song, Guo-Hai Chen, Bing-Heng Chen, Nai-Qing Zhao, and Hai-Dong Kan. 2007. "A Time Series Analysis of Outdoor Air Pollution and Preterm Birth in Shanghai, China." Biomedical and environmental sciences: BES 20, no. 5 (October): 426-431. https://pubmed.ncbi.nlm.nih.gov/18188997/.

Klepac, Petra, Igor Locatelli, Sara Korošec, Nino Künzli, and Andreja Kukec. 2018. “Ambient Air Pollution and Pregnancy Outcomes: A Comprehensive Review and Identification of Environmental Public Health Challenges." Environmental Research 167 (November): 144159. https://doi.org/10.1016/j.envres.2018.07.008.

Kloog, Itai, Steven J. Melly, Brent A. Coull, Francesco Nordio, and Joel D. Schwartz. 2015. "Using Satellite-Based Spatiotemporal Resolved Air Temperature Exposure to Study the Association Between Ambient Air Temperature and Birth Outcomes in Massachusetts." Environmental Health Perspectives 123, no. 10 (October): 1053-1058. https://doi.org/10. 1289/ehp.1308075.

Koenker, Roger. 2020. Quantreg: Quantile Regression. https://CRAN.R-project.org/package= quantreg. 
Koenker, Roger, and Kevin F Hallock. 2001. "Quantile Regression.” Journal of Economic Perspectives 15, no. 4 (November): 143-156. https://doi.org/10.1257/jep.15.4.143.

Kothari, Catherine L., Rajib Paul, Ben Dormitorio, Fernando Ospina, Arthur James, Deb Lenz, Kathleen Baker, et al. 2016. "The Interplay of Race, Socioeconomic Status and Neighborhood Residence Upon Birth Outcomes in a High Black Infant Mortality Community." SSM - Population Health 2 (December): 859-867. https://doi.org/10.1016/j.ssmph.2016.09.011.

Lamichhane, Dirga Kumar, So-Yeon Lee, Kangmo Ahn, Kyung Won Kim, Youn Ho Shin, Dong In Suh, Soo-Jong Hong, et al. 2020. "Quantile Regression Analysis of the Socioeconomic Inequalities in Air Pollution and Birth Weight." Environment International 142 (September): 105875. https://doi.org/10.1016/j.envint.2020.105875.

Lin, Hualiang, Zhijiang Liang, Tao Liu, Qian Di, Zhengmin Qian, Weilin Zeng, Jianpeng Xiao, et al. 2015. "Association Between Exposure to Ambient Air Pollution Before Conception Date and Likelihood of Giving Birth to Girls in Guangzhou, China." Atmospheric Environment 122 (December): 622-627. https://doi.org/10.1016/j.atmosenv.2015.10.035.

Lin, Hualiang, Jun Tao, Haidong Kan, Zhengmin Qian, Ailan Chen, Yaodong Du, Tao Liu, et al. 2018. "Ambient Particulate Matter Air Pollution Associated with Acute Respiratory Distress Syndrome in Guangzhou, China.” Journal of Exposure Science \& Environmental Epidemiology 28, no. 4 (June): 392-399. https://doi.org/10.1038/s41370-018-0034-0.

Liu, Xiaoying, Huazhang Miao, Jere R. Behrman, Emily Hannum, Zhijiang Liang, and Qingguo Zhao. 2022. "The Asian Games, Air Pollution and Birth Outcomes in South China: An Instrumental Variable Approach." Economics \& Human Biology 44:101078. https://doi.org/ 10.1016/j.ehb.2021.101078.

Liu, Ying, Jihong Xu, Dian Chen, Pei Sun, and Xu Ma. 2019. "The Association Between Air Pollution and Preterm Birth and Low Birth Weight in Guangdong, China." BMC Public Health 19, no. 1 (December). https://doi.org/10.1186/s12889-018-6307-7.

Melody, Shannon M., Jane Ford, Karen Wills, Alison Venn, and Fay H. Johnston. 2019. "Maternal Exposure to Short-to Medium-Term Outdoor Air Pollution and Obstetric and Neonatal Outcomes: A Systematic Review." Environmental Pollution 244 (January): 915-925. https: //doi.org/10.1016/j.envpol.2018.10.086.

Morello-Frosch, Rachel, Bill M. Jesdale, James L. Sadd, and Manuel Pastor. 2010. “Ambient Air Pollution Exposure and Full-Term Birth Weight in California.” Environmental Health 9, no. 1 (July): 44. https://doi.org/10.1186/1476-069X-9-44.

National Bureau of Statistics of China. 2021. "Communiqué of the Seventh National Population Census (No. 6),” May 11, 2021. http://www.stats.gov.cn/english/PressRelease/202105/ t20210510_1817191.html.

National Oceanic and Atmospheric Administration. 2020. Global Historical Climatology Network $(G H C N)$. Data Warehouse. https://www.ncdc.noaa.gov/data-access/land-basedstation-data/land-based-datasets/global-historical-climatology-network-ghen.

Ogasawara, Kota, and Minami Yumitori. 2019. "Early-Life Exposure to Weather Shocks and Child Height: Evidence from Industrializing Japan.” SSM - Population Health 7 (April): 100317. https://doi.org/10.1016/j.ssmph.2018.11.001.

Raspisaniye Pogodi Ltd. 2020. Weather for 6,645 Locations in China. Weather information. https://rp5.ru/Weather_in_China.

Rich, David Q., Kaibo Liu, Jinliang Zhang, Sally W. Thurston, Timothy P. Stevens, Ying Pan, Cathleen Kane, et al. 2015. "Differences in Birth Weight Associated with the 2008 Beijing 
Olympics Air Pollution Reduction: Results from a Natural Experiment." Environmental Health Perspectives 123, no. 9 (September): 880-887. https://doi.org/10.1289/ehp.1408795.

Rocha, Rudi, and Rodrigo R. Soares. 2015. "Water Scarcity and Birth Outcomes in the Brazilian Semiarid." Journal of Development Economics 112 (January): 72-91. https://doi.org/10. 1016/j.jdeveco.2014.10.003.

Sagiv, Sharon K, Pauline Mendola, Dana Loomis, Amy H Herring, Lucas M Neas, David A Savitz, and Charles Poole. 2005. "A Time Series Analysis of Air Pollution and Preterm Birth in Pennsylvania, 1997-2001.” Environmental Health Perspectives 113, no. 5 (May): 602-606. https://doi.org/10.1289/ehp.7646.

Sauer, Mark V. 2015. "Reproduction at an Advanced Maternal Age and Maternal Health." Fertility and Sterility 103, no. 5 (May): 1136-1143. https://doi.org/10.1016/j.fertnstert. 2015.03.004.

Schifano, Patrizia, Adele Lallo, Federica Asta, Manuela De Sario, Marina Davoli, and Paola Michelozzi. 2013. "Effect of Ambient Temperature and Air Pollutants on the Risk of Preterm Birth, Rome 2001-2010.” Environment International 61 (November): 77-87. https: //doi.org/10.1016/j.envint.2013.09.005.

Schwarz, Lara, Tim Bruckner, Sindana D. Ilango, Paige Sheridan, Rupa Basu, and Tarik Benmarhnia. 2019. "A Quantile Regression Approach to Examine Fine Particles, Term Low Birth Weight, and Racial/ethnic Disparities:" Environmental Epidemiology 3, no. 4 (August): e060. https://doi.org/10.1097/EE9.0000000000000060.

Shah, Prakesh S., and Taiba Balkhair. 2011. "Air Pollution and Birth Outcomes: A Systematic Review." Environment International 37, no. 2 (February): 498-516. https://doi.org/10. 1016/j.envint.2010.10.009.

Son, Ji-Young, Jong-Tae Lee, Kevin J. Lane, and Michelle L. Bell. 2019. "Impacts of High Temperature on Adverse Birth Outcomes in Seoul, Korea: Disparities by Individual- and Community-Level Characteristics." Environmental Research 168 (January): 460-466. https: //doi.org/10.1016/j.envres.2018.10.032.

Stieb, David M., Li Chen, Maysoon Eshoul, and Stan Judek. 2012. “Ambient Air Pollution, Birth Weight and Preterm Birth: A Systematic Review and Meta-Analysis." Environmental Research 117 (August): 100-111. https://doi.org/10.1016/j.envres.2012.05.007.

Strand, Linn Beate, Adrian G Barnett, and Shilu Tong. 2011. "Methodological Challenges When Estimating the Effects of Season and Seasonal Exposures on Birth Outcomes." BMC Medical Research Methodology 11, no. 1 (December). https://doi.org/10.1186/1471-228811-49.

Strickland, Matthew J., Ying Lin, Lyndsey A. Darrow, Joshua L. Warren, James A. Mulholland, and Howard H. Chang. 2019. "Associations Between Ambient Air Pollutant Concentrations and Birth Weight: A Quantile Regression Analysis.” Epidemiology 30, no. 5 (September): 624-632. https://doi.org/10.1097/EDE.0000000000001038.

Suh, Young Ju, Ho Kim, Ju Hee Seo, Hyesook Park, Young Ju Kim, Yun Chul Hong, and Eun Hee Ha. 2009. "Different Effects of PM10 Exposure on Preterm Birth by Gestational Period Estimated from Time-Dependent Survival Analyses." International Archives of Occupational and Environmental Health 82, no. 5 (April): 613-621. https://doi.org/10. 1007/s00420-008-0380-7.

Torche, Florencia, and Dalton Conley. 2016. "A Pound of Flesh: The Use of Birthweight as a Measure of Human Capital Endowment in Economics Research.” In The Oxford Handbook 
of Economics and Human Biology, edited by John Komlos and Inas R. Kelly, 631-649. Oxford University Press, May. https://doi.org/10.1093/oxfordhb/9780199389292.013.26.

Wang, Qiong, Bing Li, Tarik Benmarhnia, Shakoor Hajat, Meng Ren, Tao Liu, Luke D. Knibbs, et al. 2020. "Independent and Combined Effects of Heatwaves and PM2.5 on Preterm Birth in Guangzhou, China: A Survival Analysis." Environmental Health Perspectives 128, no. 1 (January): 017006. https://doi.org/10.1289/EHP5117.

Westergaard, Nadja, Ulrike Gehring, Rémy Slama, and Marie Pedersen. 2017. "Ambient Air Pollution and Low Birth Weight - Are Some Women More Vulnerable Than Others?" Environment International 104 (July): 146-154. https://doi.org/10.1016/j.envint.2017.03. 026.

World Health Organization. 2018a. Ambient (outdoor) Air Pollution. Fact Sheet. Geneva: World Health Organization. https://www. who. int/news - room/fact - sheets/detail/ambient(outdoor)-air-quality-and-health.

- 2018b. Protecting Health from Rising Temperatures and Extreme Heat - WHO Factsheet on Heat and Health. Fact Sheet. Geneva: World Health Organization, June. https://www. who.int/news-room/fact-sheets/detail/climate-change-heat-and-health.

Wu, Kaipu, Huanqing Hu, Zhoupeng Ren, Tarik Benmarhnia, Meng Ren, Simin He, Luke D. Knibbs, et al. 2021. "Effects of Maternal Exposure to Fine Particulate Matter on Birth Weight in 16 Counties Across China: A Quantile Regression Analysis." 16, no. 5 (May): 055014. https://doi.org/10.1088/1748-9326/abf58c.

Yu, Xiumei, Xiaoyan Lei, and Min Wang. 2019. "Temperature Effects on Mortality and Household Adaptation: Evidence from China." Journal of Environmental Economics and Management 96:195-212. https://doi.org/https://doi.org/10.1016/j.jeem.2019.05.004.

Zhang, Junjie, and Quan Mu. 2018. "Air Pollution and Defensive Expenditures: Evidence from Particulate-Filtering Facemasks." Journal of Environmental Economics and Management 92 (November): 517-536. https://doi.org/10.1016/j.jeem.2017.07.006.

Zhang, Rong, Zhao-Yue Chen, Chun-Quan Ou, and Yan Zhuang. 2017. "Trends of Heat Waves and Cold Spells Over 1951-2015 in Guangzhou, China." Atmosphere 8, no. 12 (February): 37. https://doi.org/10.3390/atmos8020037.

Zhang, Yunquan, Chuanhua Yu, and Lu Wang. 2017. "Temperature Exposure During Pregnancy and Birth Outcomes: An Updated Systematic Review of Epidemiological Evidence." Environmental Pollution 225 (June): 700-712. https://doi.org/10.1016/j.envpol.2017.02.066.

Zhao, Nan, Jie Qiu, Yaqun Zhang, Xiaochun He, Min Zhou, Min Li, Xiaoying Xu, et al. 2015. "Ambient Air Pollutant PM10 and Risk of Preterm Birth in Lanzhou, China." Environment International 76 (March): 71-77. https://doi.org/10.1016/j.envint.2014.12.009.

Zhao, Qingguo, Zhijiang Liang, Shijuan Tao, Juan Zhu, and Yukai Du. 2011. "Effects of Air Pollution on Neonatal Prematurity in Guangzhou of China: A Time-Series Study." Environmental Health 10 (2). https://ehjournal.biomedcentral.com/articles/10.1186/1476069X-10-2.

Zhong, Liuju, Peter K. K. Louie, Junyu Zheng, Zibing Yuan, Dingli Yue, Josephine W. K. Ho, and Alexis K. H. Lau. 2013. "Science-policy Interplay: Air Quality Management in the Pearl River Delta Region and Hong Kong." Atmospheric Environment, Improving Regional Air Quality over the Pearl River Delta and Hong Kong: from Science to Policy, 76 (September): 3-10. https://doi.org/10.1016/j.atmosenv.2013.03.012. 
Zhou, Xuehua, Zhaoyu Cao, Yujie Ma, Linpeng Wang, Ruidong Wu, and Wenxing Wang. 2016. "Concentrations, Correlations and Chemical Species of PM2.5/PM10 Based on Published Data in China: Potential Implications for the Revised Particulate Standard." Chemosphere 144 (February): 518-526. https://doi.org/10.1016/j.chemosphere.2015.09.003.

Zhu, Li, Rong Zhang, Shulian Zhang, Wenjing Shi, Weili Yan, Xiaoli Wang, Qin Lyu, et al. 2015. "Chinese Neonatal Birth Weight Curve for Different Gestational Age." Chinese Journal of Pediatrics 53, no. 2 (February). https://pubmed.ncbi.nlm.nih.gov/25876683/. 
Fig. 1. Daily mean ambient air pollution levels for three major pollutants, 2008 to 2011, Guangzhou, China.
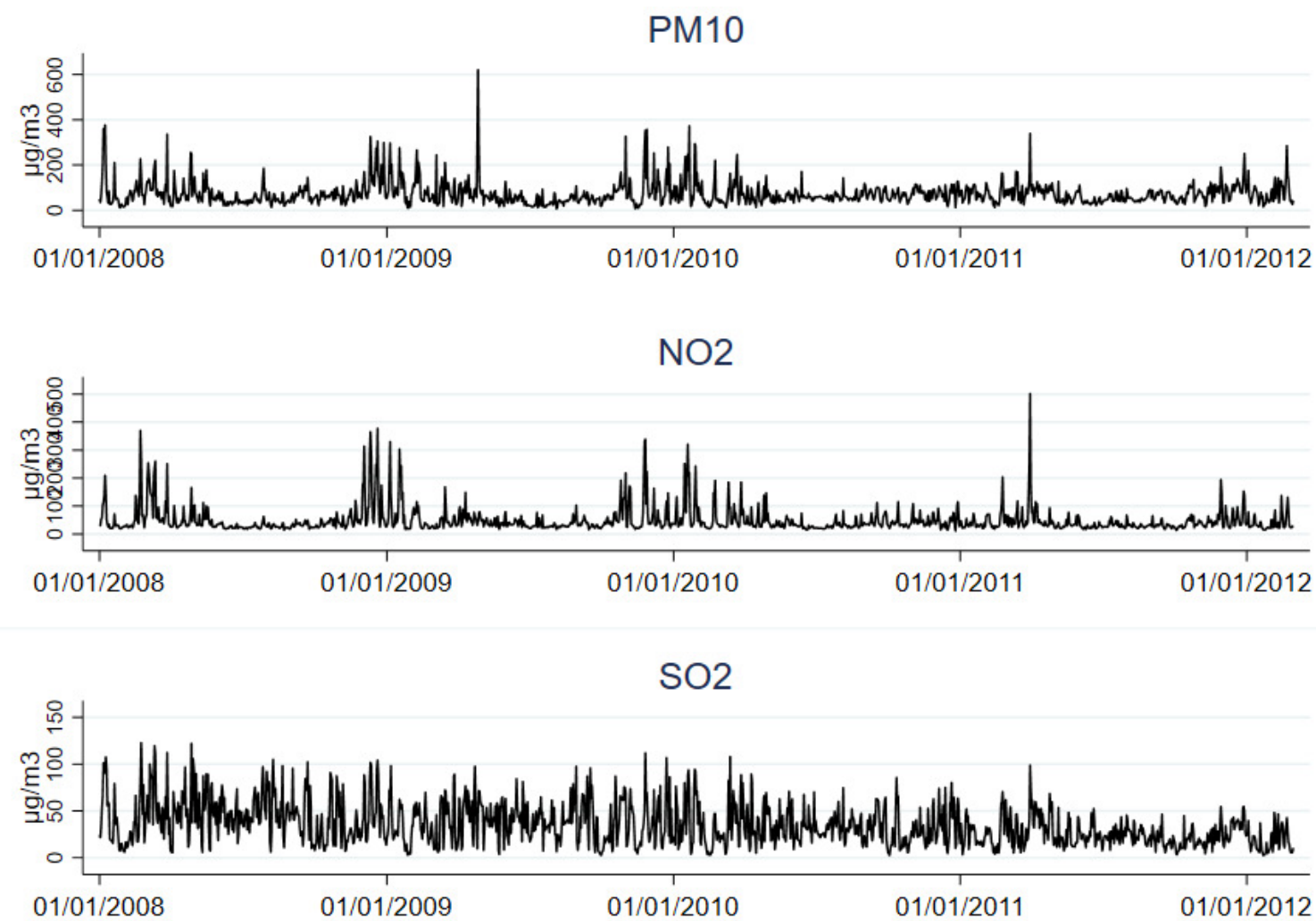

Note: This figure shows daily means for three monitored ambient air pollutants in Guangzhou between 2008 and 2011. 
Fig. 2. Daily mean temperature (Universal Thermal Climate Index), Guangzhou, China, 2008 to 2011.

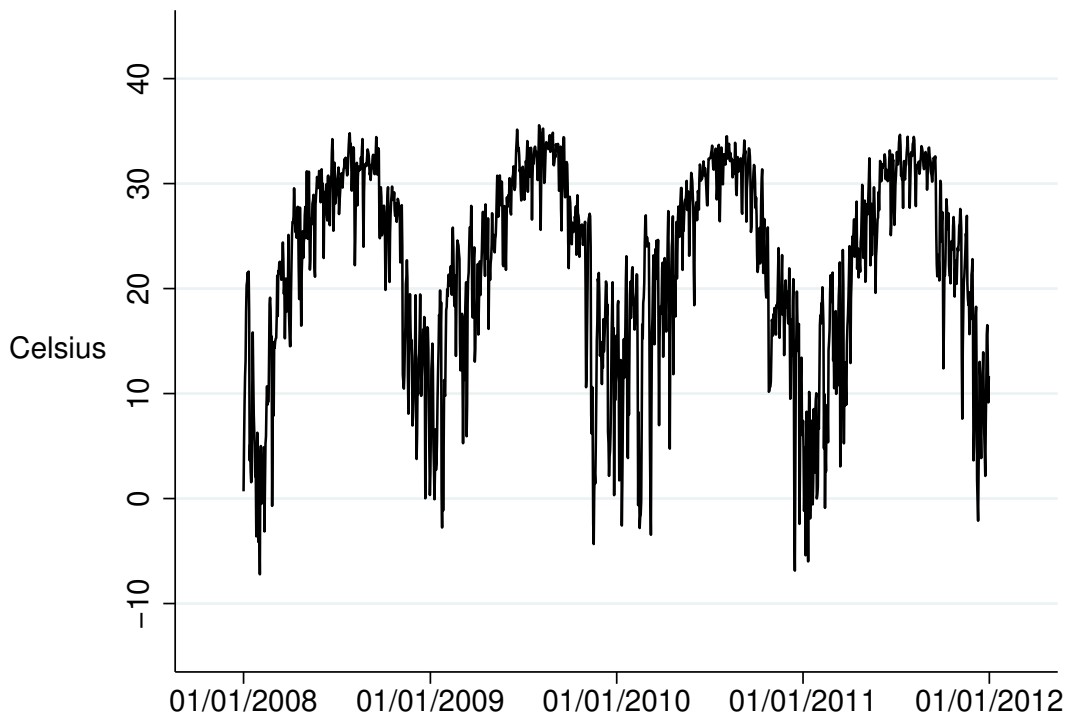

37 
Fig. 3. Daily mean ambient $\mathrm{PM}_{10}$ exposure by mother's education.
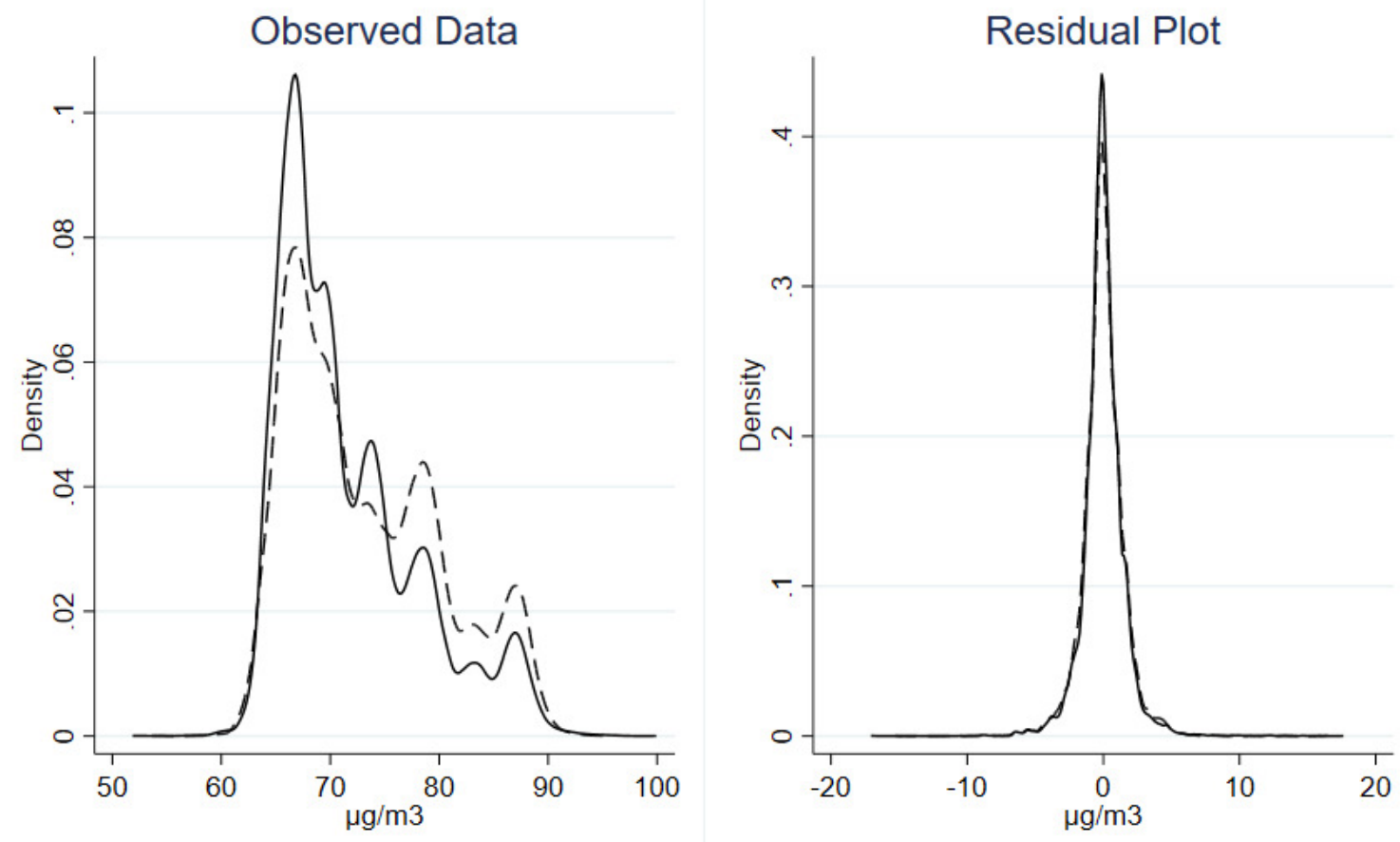

$$
\begin{array}{ll}
- \text { High school or less } \\
----- & \text { College educated }
\end{array}
$$

Note: The left panel contains observed data, while the right panel depicts the conditional distribution of daily mean ambient $\mathrm{PM}_{10}$ exposure after controlling for conception year and month interaction fixed effects. 
Fig. 4. Graphical illustration of mean and conditional quantile estimation coefficients from models of birth weight (grams) for average daily mean ambient $\mathrm{PM}_{10}$ exposures $\left(\mu \mathrm{g} / \mathrm{m}^{3}\right)$ (top row) and composite index (bottom row) for mothers with college education and mothers with high school or less education (HS).

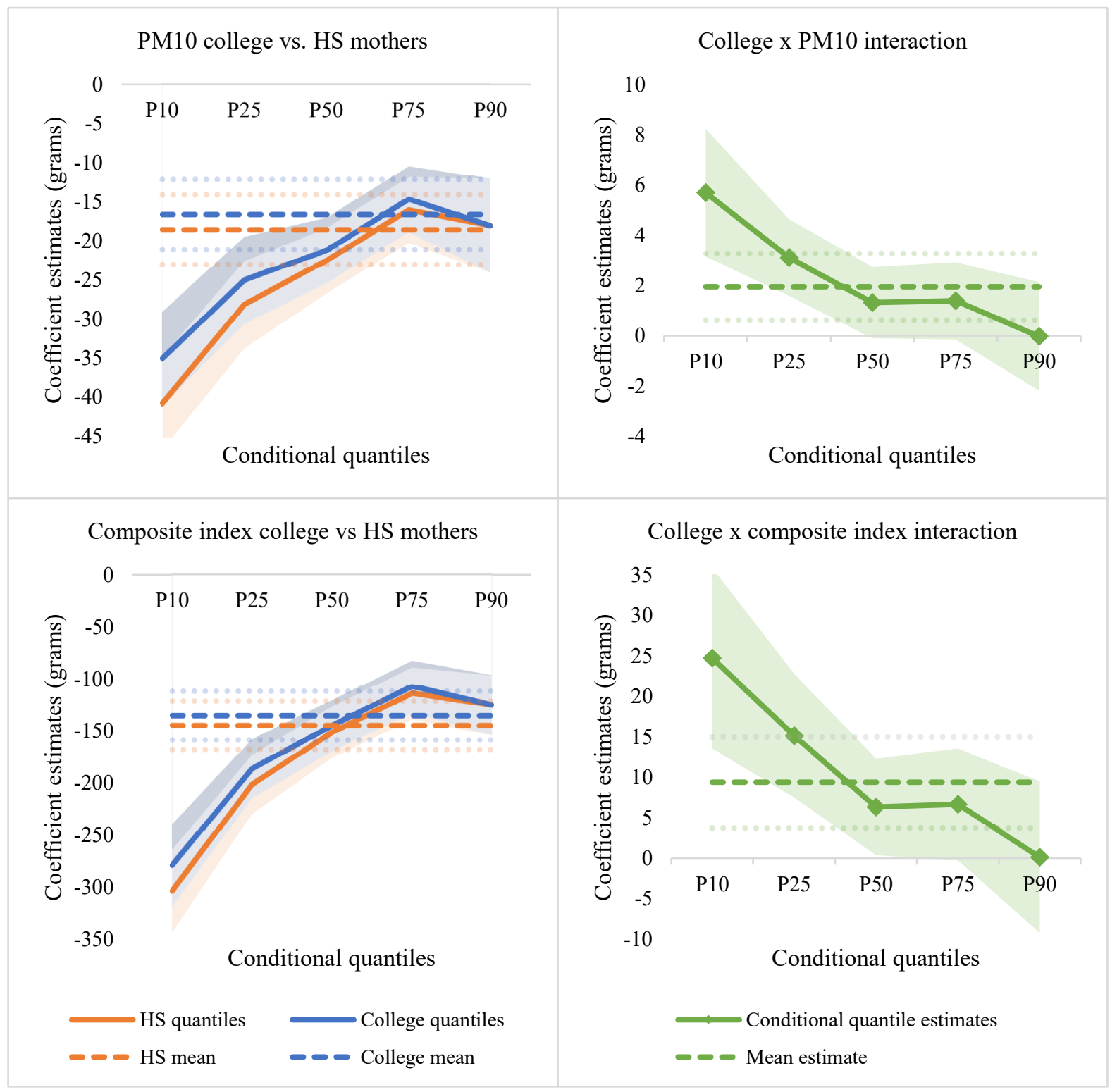

Note: The $\mathrm{x}$-axis of the sub-plots corresponds to results from different conditional quantile estimations. We interpret lower conditional quantiles as corresponding to higher levels of unobserved innate vulnerabilities for babies. The two subfigures in the top panel are based on estimates from Tables 3 and 5. The two subfigures in the bottom panel are based on estimates from Appendix Tables A.1 and A.3. The y-axis reports regression coefficients. The left and right panels depict the same information in two ways. The solid line in the right panel shows the gap between the HS and college quantile coefficient lines in the corresponding left panel. The gaps depicted on the right provide a visualization of the maternal college education and pollution interaction coefficients, from Table 5 in the top panel for $\mathrm{PM}_{10}$ or from Table A. 3 for the composite index. In the top panel, coefficients indicate grams of birth weight change for each additional $\mu \mathrm{g} / \mathrm{m}^{3}$ of average daily mean ambient $\mathrm{PM}_{10}$ exposures. In the bottom panel, coefficients indicate grams of birth weight change for each additional index unit of the composite index. 
Fig. 5. Graphical illustration of predicted college premium in birth weight for different conditional quantiles and at different ambient $\mathrm{PM}_{10}$ exposure levels.

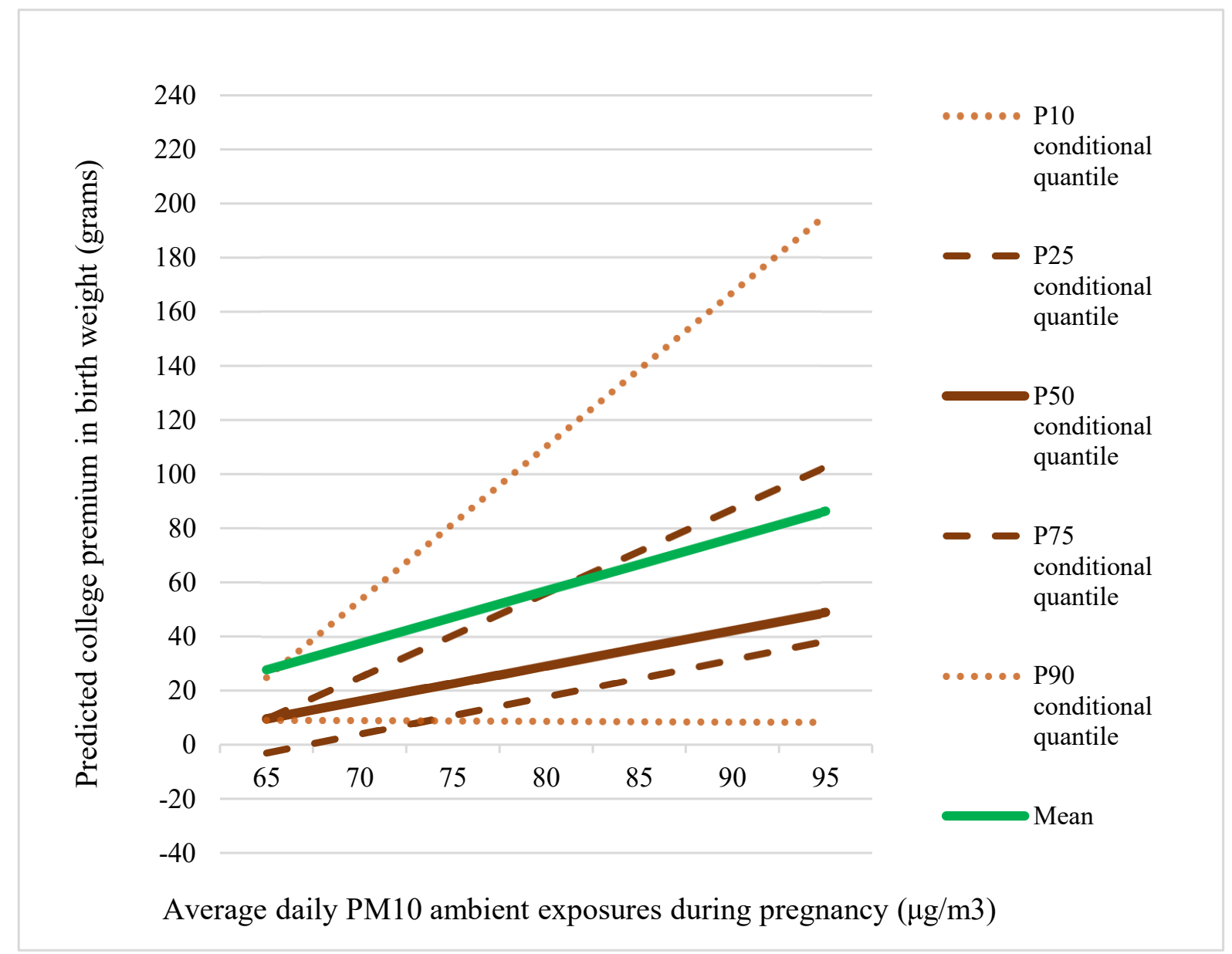

Note: The $\mathrm{x}$-axis of the figure represents different ambient $\mathrm{PM}_{10}$ exposure levels during the course of pregnancy, which correspond to the range of ambient $\mathrm{PM}_{10}$ exposure levels reported in Table 2. The $y-$ axis reports predicted college premium in birth weight-the predicted gap in birth weight between collegeeducated and non-college-educated mothers. Given estimates from Tables 3 and 5, each line corresponds to predictions for children at differing conditional quantiles. The premium is greater at higher ambient exposure levels and for children with higher levels of unobserved innate vulnerabilities-those at lower conditional quantiles. 
Table 1: Summary statistics.

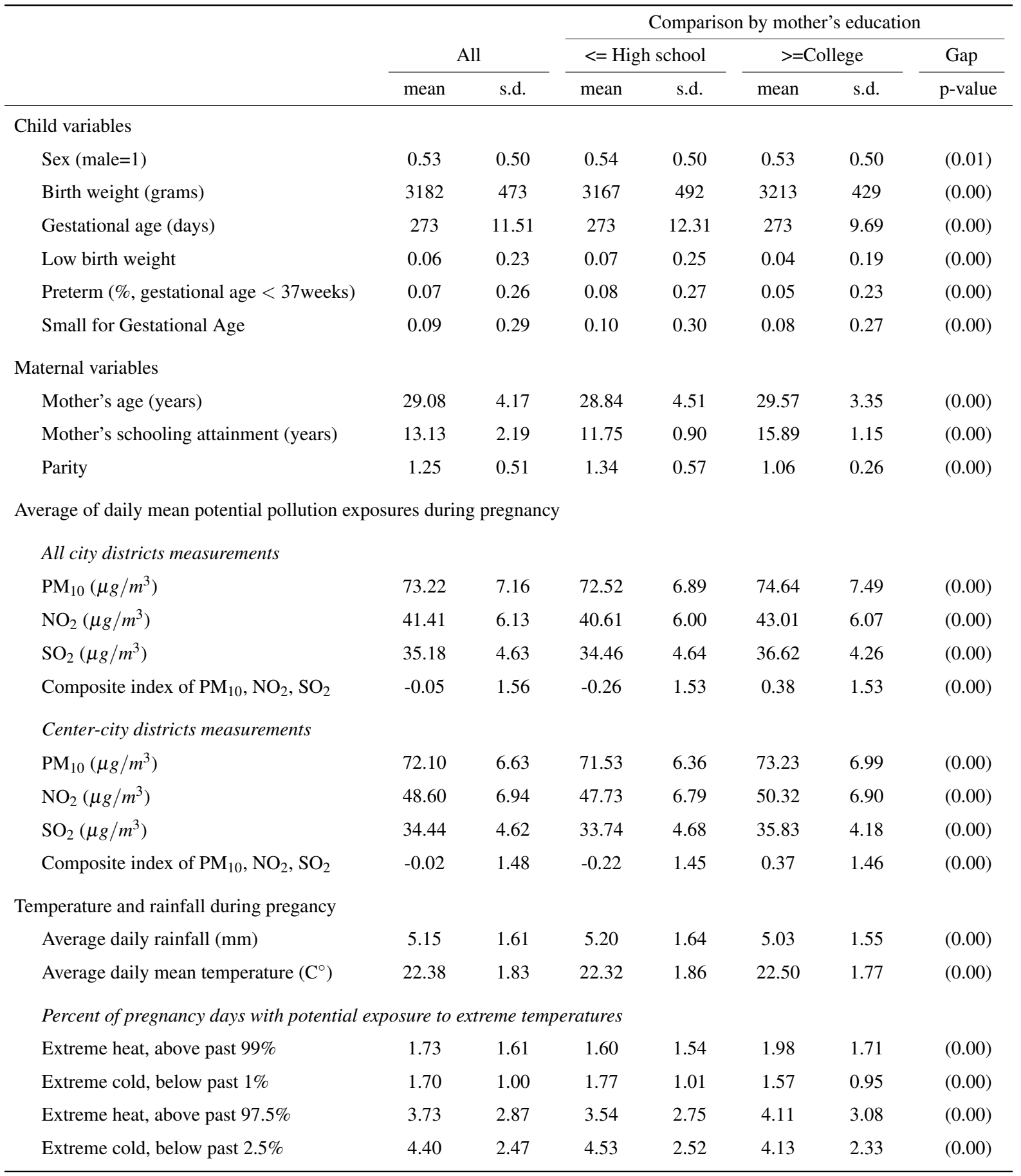

Note: The analytic sample has 53,879 observations. The college subsample has 17,967 observations and the high school or lower subsample has 35,912 observations. Sources and computations for ambient environmental variables are discussed in the data section of the paper.

$\doteqdot$ P-value from testing whether the mean gap for each variable between college-educated and non-college-educated mothers is statistically different. 
Table 2: Distribution of cumulative ambient $\mathrm{PM}_{10}$, composite index and extreme temperature exposures during the course of pregnancy.

\begin{tabular}{|c|c|c|c|c|c|c|}
\hline \multirow[b]{3}{*}{ Statistics } & \multirow{2}{*}{\multicolumn{2}{|c|}{ Pollution measures }} & \multicolumn{4}{|c|}{ Varying cutoffs for extreme temperature exposures } \\
\hline & & & \multicolumn{2}{|c|}{1 percent cutoff } & \multicolumn{2}{|c|}{2.5 percent cutoff } \\
\hline & $\begin{array}{l}\mathrm{PM}_{10} \\
\mu g / m^{3}\end{array}$ & $\begin{array}{c}\text { composite } \\
\text { index }\end{array}$ & $\begin{array}{c}\text { heat } \\
\text { percent days }\end{array}$ & $\begin{array}{c}\text { cold } \\
\text { percent days }\end{array}$ & $\begin{array}{c}\text { heat } \\
\text { percent days }\end{array}$ & $\begin{array}{c}\text { cold } \\
\text { percent days }\end{array}$ \\
\hline \multicolumn{7}{|c|}{ Percentiles } \\
\hline P1 & 63.05 & -2.31 & 0.00 & 0.00 & 0.00 & 0.00 \\
\hline P5 & 64.50 & -2.18 & 0.00 & 0.36 & 0.00 & 0.37 \\
\hline P10 & 65.10 & -1.71 & 0.00 & 0.43 & 0.38 & 1.08 \\
\hline $\mathrm{P} 25$ & 66.80 & -1.33 & 0.71 & 0.73 & 1.75 & 2.50 \\
\hline P50 & 70.01 & -0.25 & 0.76 & 1.79 & 2.59 & 4.23 \\
\hline P75 & 76.41 & 1.20 & 3.65 & 2.63 & 6.88 & 6.83 \\
\hline P90 & 82.56 & 2.29 & 4.38 & 2.93 & 8.39 & 7.33 \\
\hline P95 & 86.45 & 2.66 & 4.48 & 3.00 & 8.58 & 7.49 \\
\hline P99 & 88.52 & 2.92 & 4.71 & 3.17 & 9.02 & 7.94 \\
\hline \multicolumn{7}{|c|}{ Min and Max } \\
\hline Min & 51.86 & -2.42 & 0.00 & 0.00 & 0.00 & 0.00 \\
\hline $\operatorname{Max}$ & 99.91 & 4.86 & 6.35 & 4.35 & 12.17 & 10.87 \\
\hline
\end{tabular}

Note: Figures reported in the table represent distributional statistics along the marginal distribution of ambient pollution and extreme temperature variables. 
Table 3: OLS regression analysis of birth weight with interactions of ambient $\mathrm{PM}_{10}$ and extreme temperature with maternal education.

\begin{tabular}{|c|c|c|c|c|}
\hline \multirow[b]{3}{*}{ Variable } & \multicolumn{4}{|c|}{ Varying cutoffs of extreme temperature exposures } \\
\hline & \multicolumn{2}{|c|}{1 percent cutoff } & \multicolumn{2}{|c|}{2.5 percent cutoff } \\
\hline & (1) & (2) & (3) & (4) \\
\hline \multicolumn{5}{|c|}{ Environmental exposure variables } \\
\hline \multirow[t]{2}{*}{$\mathrm{PM}_{10}$} & $-17.83^{* *}$ & $-18.58^{* *}$ & $-14.59^{* *}$ & $-15.41^{* *}$ \\
\hline & $(2.27)$ & $(2.29)$ & $(2.31)$ & $(2.33)$ \\
\hline \multirow[t]{2}{*}{ Extreme heat } & $-22.38^{*}$ & $-27.06^{* *}$ & 0.09 & -2.33 \\
\hline & $(9.41)$ & $(9.57)$ & $(5.11)$ & $(5.21)$ \\
\hline \multirow[t]{2}{*}{ Extreme cold } & $-30.84^{* *}$ & $-30.33^{* *}$ & $-24.68^{* *}$ & $-24.33^{* *}$ \\
\hline & $(9.80)$ & $(9.96)$ & $(4.37)$ & $(4.43)$ \\
\hline \multicolumn{5}{|c|}{ Education and environmental exposure interactions } \\
\hline \multirow[t]{2}{*}{ College educated } & $44.55^{* *}$ & $-115.70^{*}$ & $44.85^{* *}$ & $-133.00^{*}$ \\
\hline & $(4.43)$ & $(53.17)$ & $(4.43)$ & $(55.52)$ \\
\hline \multirow[t]{2}{*}{ College x $\mathrm{PM}_{10}$} & & $1.95^{* *}$ & & $2.19^{* *}$ \\
\hline & & $(0.68)$ & & $(0.70)$ \\
\hline \multirow[t]{2}{*}{ College $\mathrm{x}$ extreme heat } & & $11.82^{* *}$ & & $6.26^{* *}$ \\
\hline & & $(2.93)$ & & $(1.71)$ \\
\hline \multirow[t]{2}{*}{ College $\mathrm{x}$ extreme cold } & & -2.15 & & -1.35 \\
\hline & & $(4.68)$ & & $(1.87)$ \\
\hline \multicolumn{5}{|l|}{ Control variables } \\
\hline \multirow[t]{2}{*}{ Male } & $104.00^{* *}$ & $104.00^{* *}$ & $103.90^{* *}$ & $103.90^{* *}$ \\
\hline & $(3.93)$ & $(3.93)$ & (3.93) & $(3.93)$ \\
\hline \multirow[t]{2}{*}{ Mother's age } & $55.41^{* *}$ & $54.90^{* *}$ & $55.33^{* *}$ & $54.85^{* *}$ \\
\hline & $(4.98)$ & $(4.98)$ & $(4.98)$ & $(4.98)$ \\
\hline \multirow[t]{2}{*}{ Mother's age ${ }^{2}$} & $-0.90^{* *}$ & $-0.89^{* *}$ & $-0.89^{* *}$ & $-0.89^{* *}$ \\
\hline & $(0.08)$ & $(0.08)$ & $(0.08)$ & $(0.08)$ \\
\hline \multirow[t]{2}{*}{ Intercept } & $1,205.00^{* *}$ & $1,276.00^{* *}$ & $1,019.00^{* *}$ & $1,094.00^{* *}$ \\
\hline & $(219.90)$ & $(221.50)$ & $(221.40)$ & $(223.30)$ \\
\hline Observations & 53,879 & 53,879 & 53,879 & 53,879 \\
\hline $\mathrm{R}^{2}$ & 0.069 & 0.069 & 0.069 & 0.070 \\
\hline
\end{tabular}

Note: Regressions control for conception year and month interaction fixed effects, day of the week at birth, parity, and daily mean rainfall.

${ }^{\dagger} p<0.10 ;{ }^{*} p<0.05 ;{ }^{* *} p<0.01$. 
Table 4: Conditional quantile regression analysis of birth weight with ambient $\mathrm{PM}_{10}$ and extreme temperature and maternal education.

\begin{tabular}{|c|c|c|c|c|c|}
\hline \multirow[b]{2}{*}{ Variable } & \multicolumn{5}{|c|}{ Estimates at conditional quantiles } \\
\hline & P10 & $\mathrm{P} 25$ & P50 & P75 & $\mathrm{P} 90$ \\
\hline \multicolumn{6}{|c|}{ Environmental exposure variables } \\
\hline \multirow{2}{*}{$\mathrm{PM}_{10} a, b, c, d$} & $-38.90^{* *}$ & $-26.34^{* *}$ & $-22.16^{* *}$ & $-15.30^{* *}$ & $-17.50^{* *}$ \\
\hline & $(3.49)$ & $(2.44)$ & $(2.09)$ & $(2.38)$ & $(2.83)$ \\
\hline \multirow[t]{2}{*}{ Extreme heat } & -17.88 & $-13.15^{\dagger}$ & $-19.06^{*}$ & -8.10 & -7.43 \\
\hline & $(13.26)$ & $(7.84)$ & $(8.90)$ & $(11.00)$ & $(12.17)$ \\
\hline \multirow[t]{2}{*}{ Extreme cold ${ }^{a, b}$} & $-62.61^{* *}$ & $-29.79^{* *}$ & $-19.68^{*}$ & $-23.89^{*}$ & -16.82 \\
\hline & $(16.30)$ & $(9.85)$ & $(9.37)$ & $(10.15)$ & $(13.97)$ \\
\hline \multicolumn{6}{|l|}{ Education } \\
\hline \multirow[t]{2}{*}{ College educated ${ }^{a, b, c, d}$} & $64.59^{* *}$ & $33.20^{* *}$ & $21.79^{* *}$ & 9.10 & 11.19 \\
\hline & $(8.08)$ & $(5.72)$ & $(4.81)$ & $(5.87)$ & $(7.39)$ \\
\hline \multicolumn{6}{|l|}{ Control variables } \\
\hline \multirow[t]{2}{*}{ Male } & $92.62^{* *}$ & $98.92^{* *}$ & $111.94^{* *}$ & $117.30^{* *}$ & $132.60^{* *}$ \\
\hline & $(7.67)$ & $(5.07)$ & $(4.42)$ & $(4.80)$ & $(6.75)$ \\
\hline \multirow[t]{2}{*}{ Mother's age } & $64.30^{* *}$ & $45.91^{* *}$ & $46.47^{* *}$ & $51.18^{* *}$ & $46.37^{* *}$ \\
\hline & (10.01) & $(5.79)$ & $(5.63)$ & $(5.53)$ & $(8.81)$ \\
\hline \multirow[t]{2}{*}{ Mother's age ${ }^{2}$} & $-1.09^{* *}$ & $-0.73^{* *}$ & $-0.73^{* *}$ & $-0.78^{* *}$ & $-0.69^{* *}$ \\
\hline & $(0.17)$ & $(0.10)$ & $(0.09)$ & $(0.09)$ & $(0.15)$ \\
\hline \multirow[t]{2}{*}{ Intercept } & $917.89^{*}$ & $1,168.25^{* *}$ & $1,835.52^{* *}$ & $1,897.93^{* *}$ & $2,226.62^{* *}$ \\
\hline & (378.70) & $(252.98)$ & (200.27) & $(232.69)$ & (334.94) \\
\hline Observations & 53,879 & 53,879 & 53,879 & 53,879 & 53,879 \\
\hline
\end{tabular}

Note: Regressions control for conception year and month interaction fixed effects, day of the week at birth, parity, and daily mean rainfall.

Given bootstrapped simultaneous conditional quantile estimates, superscripts a, b, c, and d indicate whether estimates across conditional quantiles are statistically different for the three ambient environment or education variables.

${ }^{\text {a }}$ P10, P25, and P50 are significantly different at 0.05 sig. level.

${ }^{\mathrm{b}} \mathrm{P} 10$ and P90 are significantly different at 0.05 sig. level.

${ }^{\mathrm{c}} \mathrm{P} 25$ and P75 are significantly different at 0.05 sig. level.

${ }^{\mathrm{d}} \mathrm{P} 50, \mathrm{P} 75$, and $\mathrm{P} 90$ are significantly different at 0.05 sig. level.

${ }^{\dagger} p<0.10 ;^{*} p<0.05$; $^{* *} p<0.01$.Bootstrap standard errors are shown in parentheses. 
Table 5: Conditional quantile regression analysis of birth weight with interactions of ambient $\mathrm{PM}_{10}$ and extreme temperature with maternal education.

\begin{tabular}{|c|c|c|c|c|c|}
\hline \multirow[b]{2}{*}{ Variable } & \multicolumn{5}{|c|}{ Estimates at conditional quantiles } \\
\hline & P10 & P25 & P50 & P75 & $\mathrm{P} 90$ \\
\hline \multicolumn{6}{|c|}{ Environmental exposure variables } \\
\hline \multirow{2}{*}{$\mathrm{PM}_{10} a, b, c, d$} & $-40.75^{* *}$ & $-28.15^{* *}$ & $-22.55^{* *}$ & $-16.04^{* *}$ & $-18.06^{* *}$ \\
\hline & $(3.03)$ & $(2.83)$ & $(2.14)$ & $(2.15)$ & $(3.09)$ \\
\hline \multirow[t]{2}{*}{ Extreme heat } & $-37.30^{* *}$ & $-23.23^{*}$ & $-23.50^{* *}$ & -12.04 & -13.12 \\
\hline & $(13.73)$ & $(10.64)$ & $(8.23)$ & (10.92) & $(13.12)$ \\
\hline \multirow[t]{2}{*}{ Extreme cold ${ }^{a, b}$} & $-65.43^{* *}$ & $-28.98^{* *}$ & $-17.15^{*}$ & $-22.28^{*}$ & -13.74 \\
\hline & $(15.79)$ & $(10.57)$ & $(8.75)$ & $(10.45)$ & $(12.38)$ \\
\hline \multicolumn{6}{|c|}{ Education and environmental exposure interactions } \\
\hline \multirow[t]{2}{*}{ College educated ${ }^{a, b, c}$} & $-396.40^{* *}$ & $-216.76^{* *}$ & -83.69 & -95.51 & 2.20 \\
\hline & (99.62) & (59.02) & $(58.77)$ & $(60.23)$ & (87.96) \\
\hline \multirow[t]{2}{*}{ College x $\mathrm{PM}_{10} a, b$} & $5.69^{* *}$ & $3.11^{* *}$ & $1.31^{\dagger}$ & $1.39^{\dagger}$ & -0.02 \\
\hline & $(1.30)$ & $(0.78)$ & $(0.72)$ & $(0.78)$ & (1.10) \\
\hline \multirow[t]{2}{*}{ College $\mathrm{x}$ extreme heat ${ }^{a, b}$} & $26.35^{* *}$ & $11.83^{* *}$ & $7.30^{*}$ & 5.24 & 6.19 \\
\hline & $(5.42)$ & (3.91) & $(3.27)$ & $(3.50)$ & $(4.75)$ \\
\hline \multirow[t]{2}{*}{ College $\mathrm{x}$ extreme cold } & 3.30 & 2.21 & -2.68 & -3.97 & -1.34 \\
\hline & $(9.12)$ & $(6.28)$ & $(4.94)$ & $(5.87)$ & (7.69) \\
\hline \multicolumn{6}{|l|}{ Control variables } \\
\hline \multirow[t]{2}{*}{ Male } & $90.14^{* *}$ & $98.32^{* *}$ & $112.02^{* *}$ & $116.40^{* *}$ & $132.55^{* *}$ \\
\hline & $(8.38)$ & $(5.15)$ & $(4.42)$ & (5.15) & $(6.12)$ \\
\hline \multirow[t]{2}{*}{ Mother's age } & $62.49^{* *}$ & $44.68^{* *}$ & $46.26^{* *}$ & $48.33^{* *}$ & $45.30^{* *}$ \\
\hline & $(10.02)$ & $(6.04)$ & $(5.07)$ & $(5.70)$ & $(8.91)$ \\
\hline \multirow[t]{2}{*}{ Mother's age ${ }^{2}$} & $-1.06^{* *}$ & $-0.71^{* *}$ & $-0.73^{* *}$ & $-0.74^{* *}$ & $-0.67^{* *}$ \\
\hline & $(0.17)$ & $(0.10)$ & $(0.09)$ & $(0.10)$ & $(0.15)$ \\
\hline \multirow[t]{2}{*}{ Intercept } & $1,240.85^{* *}$ & $1,415.85^{* *}$ & $1,888.54^{* *}$ & $2,032.87^{* *}$ & $2,357.66^{* *}$ \\
\hline & (371.67) & $(263.70)$ & $(206.46)$ & (202.99) & $(369.89)$ \\
\hline Observations & 53,879 & 53,879 & 53,879 & 53,879 & 53,879 \\
\hline
\end{tabular}

Note: Regressions control for conception year and month interaction fixed effects, day of the week at birth, parity, and daily mean rainfall.

Given bootstrapped simultaneous conditional quantile estimates, superscripts a, b, c, and d indicate whether estimates across conditional quantiles are statistically different for the three ambient environment or education variables.

${ }^{a} \mathrm{P} 10, \mathrm{P} 25$, and P50 are significantly different at 0.05 sig. level.

${ }^{\mathrm{b}} \mathrm{P} 10$ and P90 are significantly different at 0.05 sig. level.

${ }^{\mathrm{c}} \mathrm{P} 25$ and P75 are significantly different at 0.05 sig. level.

${ }^{\mathrm{d}} \mathrm{P} 50, \mathrm{P} 75$, and P90 are significantly different at 0.05 sig. level.

${ }^{\dagger} p<0.10 ;^{*} p<0.05$; $^{* *} p<0.01$.Bootstrap standard errors are shown in parentheses. 


\section{ONLINE APPENDIX}

\section{Same environment, stratified impacts? Air pollution, extreme temperatures, and birth weight in south China}

Xiaoying Liu, Jere R. Behrman, Emily Hannum, Fan Wang, and Qingguo Zhao

\section{A Additional Estimation Results}

\section{A.1 Composite Pollution Index}

In this Appendix section, we repeat the analyses for $\mathrm{PM}_{10}$ with the composite index pollution measure. Results are presented in Appendix Tables A.1, A.2 and A.3. Patterns in the temperature results are robust to choice of pollution measure. The results from the composite index analysis closely mirror the patterns revealed in the $\mathrm{PM}_{10}$ analysis. There is a protective effect of maternal education with regard to pollution, and the finding persists across conditional quantiles of birth weight (see the dotted lines in Figure 4 Bottom Row). Further, quantile regressions show that the negative associations between the pollution and birth weight, and the protective effects of maternal education with respect to pollution, are magnified at lower conditional quantiles (see the solid lines and shaded areas in Figure 4 Bottom Row). See Section 4.3 for more discussion. 
Table A.1: OLS regression analysis of birth weight with interactions of ambient composite index and extreme temperature with maternal education.

\begin{tabular}{|c|c|c|c|c|}
\hline \multirow[b]{3}{*}{ Variable } & \multicolumn{4}{|c|}{ Varying cutoffs of extreme temperature exposures } \\
\hline & \multicolumn{2}{|c|}{1 percent cutoff } & \multicolumn{2}{|c|}{2.5 percent cutoff } \\
\hline & (1) & (2) & (3) & (4) \\
\hline \multicolumn{5}{|l|}{ Environmental exposure variables } \\
\hline Composite index & $\begin{array}{c}-140.90^{* *} \\
(11.82)\end{array}$ & $\begin{array}{c}-144.50^{* *} \\
(11.90)\end{array}$ & $\begin{array}{c}-127.10^{* *} \\
(11.88)\end{array}$ & $\begin{array}{r}-131.00^{* *} \\
(11.95)\end{array}$ \\
\hline Extreme heat & $\begin{array}{c}-28.61^{* *} \\
(9.49)\end{array}$ & $\begin{array}{c}-32.21^{* *} \\
(9.64)\end{array}$ & $\begin{array}{l}-4.47 \\
(5.06)\end{array}$ & $\begin{array}{l}-6.28 \\
(5.16)\end{array}$ \\
\hline Extreme cold & $\begin{array}{c}-27.97^{* *} \\
(9.76)\end{array}$ & $\begin{array}{c}-27.43^{* *} \\
(9.92)\end{array}$ & $\begin{array}{c}-23.38^{* *} \\
(4.36)\end{array}$ & $\begin{array}{c}-23.04^{* *} \\
(4.42)\end{array}$ \\
\hline \multicolumn{5}{|c|}{ Education and environmental exposure interactions } \\
\hline College educated & $\begin{array}{c}44.61^{* *} \\
(4.43)\end{array}$ & $\begin{array}{l}29.45^{* *} \\
(11.15)\end{array}$ & $\begin{array}{c}44.89^{* *} \\
(4.43)\end{array}$ & $\begin{array}{l}29.82^{*} \\
(12.06)\end{array}$ \\
\hline College $\mathrm{x}$ composite index & & $\begin{array}{l}9.38^{* *} \\
(2.87)\end{array}$ & & $\begin{array}{c}10.43^{* *} \\
(2.84)\end{array}$ \\
\hline College $\mathrm{x}$ extreme heat & & $\begin{array}{l}9.19^{* *} \\
(2.77)\end{array}$ & & $\begin{array}{l}4.73^{* *} \\
(1.57)\end{array}$ \\
\hline College $\mathrm{x}$ extreme cold & & $\begin{array}{l}-2.25 \\
(4.68)\end{array}$ & & $\begin{array}{l}-1.28 \\
(1.87)\end{array}$ \\
\hline Control variables & & & & \\
\hline Male & $\begin{array}{c}104.30^{* *} \\
(3.92)\end{array}$ & $\begin{array}{c}104.30^{* *} \\
(3.92)\end{array}$ & $\begin{array}{c}104.20^{* *} \\
(3.92)\end{array}$ & $\begin{array}{c}104.20^{* *} \\
(3.92)\end{array}$ \\
\hline Mother's age & $\begin{array}{c}55.11^{* *} \\
(4.97)\end{array}$ & $\begin{array}{c}54.54^{* *} \\
(4.97)\end{array}$ & $\begin{array}{c}55.07^{* *} \\
(4.97)\end{array}$ & $\begin{array}{c}54.51^{* *} \\
(4.97)\end{array}$ \\
\hline Mother's age ${ }^{2}$ & $\begin{array}{c}-0.89^{* *} \\
(0.08)\end{array}$ & $\begin{array}{c}-0.88^{* *} \\
(0.08)\end{array}$ & $\begin{array}{c}-0.89^{* *} \\
(0.08)\end{array}$ & $\begin{array}{c}-0.88^{* *} \\
(0.08)\end{array}$ \\
\hline Intercept & $\begin{array}{l}-218.50 \\
(136.30)\end{array}$ & $\begin{array}{l}-203.60 \\
(136.40)\end{array}$ & $\begin{array}{l}-147.60 \\
(136.80)\end{array}$ & $\begin{array}{l}-133.10 \\
(136.90)\end{array}$ \\
\hline $\begin{array}{l}\text { Observations } \\
\mathrm{R}^{2}\end{array}$ & $\begin{array}{c}53,879 \\
0.071\end{array}$ & $\begin{array}{c}53,879 \\
0.072\end{array}$ & $\begin{array}{c}53,879 \\
0.072\end{array}$ & $\begin{array}{c}53,879 \\
0.072 \\
\end{array}$ \\
\hline
\end{tabular}

Note: Regressions control for conception year and month interaction fixed effects, day of the week at birth, parity, and daily mean rainfall.

${ }^{\dagger} p<0.10 ;{ }^{*} p<0.05 ;{ }^{* *} p<0.01$. 
Table A.2: Conditional quantile regression analysis of birth weight with ambient composite index and extreme temperature and maternal education.

\begin{tabular}{|c|c|c|c|c|c|}
\hline \multirow[b]{2}{*}{ Variable } & \multicolumn{5}{|c|}{ Estimates at conditional quantiles } \\
\hline & P10 & $\mathrm{P} 25$ & P50 & P75 & $\mathrm{P} 90$ \\
\hline \multicolumn{6}{|c|}{ Environmental exposure variables } \\
\hline \multirow[t]{2}{*}{ Composite index ${ }^{a, b, c, d}$} & $-292.98^{* *}$ & $-192.96^{* *}$ & $-150.52^{* *}$ & $-111.98^{* *}$ & $-123.83^{* *}$ \\
\hline & $(19.50)$ & $(14.10)$ & $(11.00)$ & $(12.61)$ & $(17.25)$ \\
\hline \multirow[t]{2}{*}{ Extreme heat } & $-38.50^{* *}$ & $-20.23^{*}$ & $-21.52^{* *}$ & -9.73 & -7.79 \\
\hline & $(14.26)$ & $(9.76)$ & $(8.01)$ & $(9.38)$ & $(14.53)$ \\
\hline \multirow[t]{2}{*}{ Extreme cold ${ }^{a, b}$} & $-58.07^{* *}$ & $-25.52^{* *}$ & $-14.43^{\dagger}$ & $-21.52^{*}$ & -12.97 \\
\hline & $(16.27)$ & $(9.62)$ & $(8.16)$ & $(10.45)$ & $(12.83)$ \\
\hline \multicolumn{6}{|l|}{ Education } \\
\hline \multirow[t]{2}{*}{ College educated ${ }^{a, b, c, d}$} & $66.01^{* *}$ & $33.64^{* *}$ & $23.00^{* *}$ & 9.63 & 9.46 \\
\hline & $(8.56)$ & $(5.72)$ & $(4.85)$ & $(6.11)$ & $(7.50)$ \\
\hline \multicolumn{6}{|l|}{ Control variables } \\
\hline \multirow[t]{2}{*}{ Male } & $92.49^{* *}$ & $99.08^{* *}$ & $112.03^{* *}$ & $117.86^{* *}$ & $131.44^{* *}$ \\
\hline & $(8.66)$ & $(4.88)$ & $(3.93)$ & $(4.90)$ & $(6.67)$ \\
\hline \multirow[t]{2}{*}{ Mother's age } & $63.22^{* *}$ & $45.16^{* *}$ & $46.75^{* *}$ & $49.19^{* *}$ & $43.76^{* *}$ \\
\hline & (10.97) & $(6.31)$ & $(5.19)$ & $(6.16)$ & $(8.42)$ \\
\hline \multirow[t]{2}{*}{ Mother's age ${ }^{2}$} & $-1.07^{* *}$ & $-0.73^{* *}$ & $-0.73^{* *}$ & $-0.75^{* *}$ & $-0.64^{* *}$ \\
\hline & $(0.19)$ & $(0.10)$ & $(0.09)$ & $(0.10)$ & $(0.14)$ \\
\hline \multirow[t]{2}{*}{ Intercept } & $-1,626.65^{* *}$ & $-564.20^{* *}$ & $260.17^{*}$ & $844.02^{* *}$ & $1,028.68^{* *}$ \\
\hline & (228.99) & $(164.71)$ & (128.89) & (163.68) & $(256.45)$ \\
\hline Observations & 53,879 & 53,879 & 53,879 & 53,879 & 53,879 \\
\hline
\end{tabular}

Note: Regressions control for conception year and month interaction fixed effects, day of the week at birth, parity, and daily mean rainfall.

Given bootstrapped simultaneous conditional quantile estimates, superscripts a, b, c, and d indicate whether estimates across conditional quantiles are statistically different for the three ambient environment or education variables.

${ }^{\text {a }}$ P10, P25, and P50 are significantly different at 0.05 sig. level.

${ }^{\mathrm{b}} \mathrm{P} 10$ and P90 are significantly different at 0.05 sig. level.

${ }^{\mathrm{c}} \mathrm{P} 25$ and P75 are significantly different at 0.05 sig. level.

${ }^{\mathrm{d}} \mathrm{P} 50, \mathrm{P} 75$, and $\mathrm{P} 90$ are significantly different at 0.05 sig. level.

${ }^{\dagger} p<0.10 ;^{*} p<0.05$; $^{* *} p<0.01$.Bootstrap standard errors are shown in parentheses. 
Table A.3: Conditional quantile regression analysis of birth weight with interactions of ambient composite index and extreme temperature with maternal education.

\begin{tabular}{|c|c|c|c|c|c|}
\hline \multirow[b]{2}{*}{ Variable } & \multicolumn{5}{|c|}{ Estimates at conditional quantiles } \\
\hline & $\mathrm{P} 10$ & P25 & P50 & P75 & P90 \\
\hline \multicolumn{6}{|l|}{ Environmental exposure variables } \\
\hline \multirow{2}{*}{ Composite index ${ }^{a, b, c, d}$} & $-303.74^{* *}$ & $-201.06^{* *}$ & $-151.02^{* *}$ & $-113.65^{* *}$ & $-125.04^{* *}$ \\
\hline & $(20.20)$ & $(14.57)$ & $(12.55)$ & $(12.82)$ & $(14.82)$ \\
\hline \multirow[t]{2}{*}{ Extreme heat ${ }^{a, b}$} & $-53.19^{* *}$ & $-26.34^{*}$ & $-23.50^{*}$ & -12.95 & -15.17 \\
\hline & $(15.83)$ & (11.66) & $(9.34)$ & $(10.00)$ & $(12.36)$ \\
\hline \multirow[t]{2}{*}{ Extreme cold ${ }^{a, b}$} & $-63.15^{* *}$ & $-26.51^{*}$ & -13.36 & $-19.48^{\dagger}$ & -11.46 \\
\hline & $(15.67)$ & $(11.10)$ & $(8.64)$ & $(10.39)$ & $(13.96)$ \\
\hline \multicolumn{6}{|c|}{ Education and environmental exposure interactions } \\
\hline \multirow[t]{2}{*}{ College educated } & 24.22 & 9.96 & 16.40 & 7.32 & -0.30 \\
\hline & $(17.25)$ & $(13.52)$ & (13.34) & $(15.17)$ & $(19.60)$ \\
\hline \multirow[t]{2}{*}{ College x composite index ${ }^{a, b, c}$} & $24.70^{* *}$ & $15.12^{* *}$ & $6.34^{*}$ & $6.63^{\dagger}$ & 0.12 \\
\hline & $(5.69)$ & $(3.90)$ & $(3.04)$ & $(3.52)$ & $(4.77)$ \\
\hline \multirow[t]{2}{*}{ College x extreme heat ${ }^{a}$} & $19.62^{* *}$ & $9.08^{*}$ & 4.80 & 3.01 & $7.33^{\dagger}$ \\
\hline & $(5.59)$ & $(3.60)$ & $(3.01)$ & $(3.44)$ & $(4.04)$ \\
\hline \multirow[t]{2}{*}{ College x extreme cold } & 3.24 & 2.74 & -3.23 & -3.38 & -1.79 \\
\hline & $(7.92)$ & $(5.31)$ & $(5.38)$ & $(6.21)$ & $(8.21)$ \\
\hline \multicolumn{6}{|l|}{ Control variables } \\
\hline \multirow[t]{2}{*}{ Male } & $88.50^{* *}$ & $98.64^{* *}$ & $111.87^{* *}$ & $117.91^{* *}$ & $131.37^{* *}$ \\
\hline & $(8.14)$ & $(4.92)$ & $(4.50)$ & $(5.04)$ & $(6.36)$ \\
\hline \multirow[t]{2}{*}{ Mother's age } & $64.58^{* *}$ & $45.67^{* *}$ & $46.16^{* *}$ & $49.16^{* *}$ & $44.13^{* *}$ \\
\hline & $(10.77)$ & $(5.67)$ & $(4.72)$ & (6.09) & $(8.70)$ \\
\hline \multirow[t]{2}{*}{ Mother's age ${ }^{2}$} & $-1.09^{* *}$ & $-0.73^{* *}$ & $-0.72^{* *}$ & $-0.75^{* *}$ & $-0.65^{* *}$ \\
\hline & $(0.18)$ & $(0.10)$ & $(0.08)$ & $(0.10)$ & $(0.15)$ \\
\hline \multirow[t]{2}{*}{ Intercept } & $-1,534.26^{* *}$ & $-562.73^{* *}$ & $273.06^{*}$ & $845.59^{* *}$ & $1,061.62^{* *}$ \\
\hline & $(246.88)$ & (159.04) & (124.02) & (150.09) & $(249.14)$ \\
\hline Observations & 53,879 & 53,879 & 53,879 & 53,879 & 53,879 \\
\hline
\end{tabular}

Note: Regressions control for conception year and month interaction fixed effects, day of the week at birth, parity, and daily mean rainfall.

Given bootstrapped simultaneous conditional quantile estimates, superscripts a, b, c, and d indicate whether estimates across conditional quantiles are statistically different for the three ambient environment or education variables.

${ }^{a} \mathrm{P} 10, \mathrm{P} 25$, and P50 are significantly different at 0.05 sig. level.

${ }^{\mathrm{b}} \mathrm{P} 10$ and $\mathrm{P} 90$ are significantly different at 0.05 sig. level.

${ }^{\mathrm{c}} \mathrm{P} 25$ and P75 are significantly different at 0.05 sig. level.

${ }^{\mathrm{d}} \mathrm{P} 50, \mathrm{P} 75$, and P90 are significantly different at 0.05 sig. level.

${ }^{\dagger} p<0.10 ;^{*} p<0.05$; $^{* *} p<0.01$.Bootstrap standard errors are shown in parentheses. 


\section{A.2 All City Districts $\mathbf{P M}_{10}$ Measurements}

Rather than using pollution data from monitoring stations in the four contiguous districts located in the center of the city, in this robustness check, we use pollution data from the whole city of Guangzhou, including information from districts that are further away. There are 11 districts in Guangzhou, five districts are located to the north of the center-city districts, and two districts are located to the south. Guangzhou city's total area is 7434 square kilometers. The four center-city districts' total area is 280 square kilometers.

Given the proximity, it is more likely that mothers who deliver in the center-city district where our data comes from reside in center-city districts. However, it is also possible that some of them come from further-away districts. Additionally, in a metropolitan city with convenient local transport networks, it is likely that Guangzhou residents travel beyond their district borders throughout the city for work, leisure, shopping, and health and other social services. So it is plausible that the appropriate measure for ambient pollution should be based on city-wide data rather than district-specific data.

Summary statistics in Table 1 shows that pollution measurements from all city districts and center-city districts are quiet similar. The mean and standard deviation of the average daily mean potential $\mathrm{PM}_{10}$ exposure are 73.2 and 7.2 for all city districts and 72.1 and 6.6 for center-city districts. The all city and center-city composite index also have similar means and standard deviations. The similarity in pollution exposure within the confines of Guangzhou is not surprising given that that these pollutants are formed and spread through lower-atmosphere and are usually not highly localized (He, Liu, and Salvo 2019).

We present results using all-city district data in Table A.4, which presents parallel results as in Table 3, except that center-city districts $\mathrm{PM}_{10}$ measurements are replaced by all city districts measurements. Table A.4 estimates are almost identical to Table 3 results. Similarly, results from using the two types of measures are also similar for conditional quantile estimations and estimation using the composite index. Given their similarity, those results are not presented. 
Table A.4: OLS regression analysis of birth weight with interactions of ambient $\mathrm{PM}_{10}$ and extreme temperature with maternal education. Using all city districts pollution measurements.

\begin{tabular}{|c|c|c|c|c|}
\hline \multirow[b]{3}{*}{ Variable } & \multicolumn{4}{|c|}{ Varying cutoffs of extreme temperature exposures } \\
\hline & \multicolumn{2}{|c|}{1 percent cutoff } & \multicolumn{2}{|c|}{2.5 percent cutoff } \\
\hline & (1) & (2) & (3) & (4) \\
\hline \multicolumn{5}{|l|}{ Environmental exposure variables } \\
\hline \multirow[t]{2}{*}{$\mathrm{PM}_{10}$ all city districts } & $-17.81^{* *}$ & $-18.55^{* *}$ & $-14.84^{* *}$ & $-15.64^{* *}$ \\
\hline & $(2.18)$ & $(2.21)$ & $(2.21)$ & $(2.24)$ \\
\hline \multirow[t]{2}{*}{ Extreme heat } & $-21.91^{*}$ & $-26.27^{* *}$ & 0.15 & -2.10 \\
\hline & $(9.51)$ & $(9.67)$ & $(5.15)$ & $(5.25)$ \\
\hline \multirow[t]{2}{*}{ Extreme cold } & $-33.55^{* *}$ & $-33.36^{* *}$ & $-25.75^{* *}$ & $-25.51^{* *}$ \\
\hline & $(9.81)$ & $(9.97)$ & $(4.37)$ & $(4.42)$ \\
\hline \multicolumn{5}{|c|}{ Education and environmental exposure interactions } \\
\hline \multirow[t]{2}{*}{ College educated } & $44.48^{* *}$ & $-117.60^{*}$ & $44.79^{* *}$ & $-132.60^{* *}$ \\
\hline & $(4.43)$ & $(48.99)$ & $(4.43)$ & $(49.90)$ \\
\hline \multirow[t]{2}{*}{ College $\mathrm{x} \mathrm{PM}_{10}$ all city districts } & & $1.96^{* *}$ & & $2.07^{* *}$ \\
\hline & & $(0.61)$ & & $(0.61)$ \\
\hline \multirow[t]{2}{*}{ College $\mathrm{x}$ extreme heat } & & $11.07^{* *}$ & & $5.83^{* *}$ \\
\hline & & $(2.85)$ & & (1.64) \\
\hline \multirow[t]{2}{*}{ College x extreme cold } & & -1.09 & & -0.97 \\
\hline & & $(4.74)$ & & $(1.89)$ \\
\hline \multicolumn{5}{|l|}{ Control variables } \\
\hline \multirow[t]{2}{*}{ Male } & $104.00^{* *}$ & $104.00^{* *}$ & $103.90^{* *}$ & $103.90^{* *}$ \\
\hline & (3.93) & $(3.93)$ & (3.93) & (3.93) \\
\hline \multirow[t]{2}{*}{ Mother's age } & $55.40^{* *}$ & $54.87^{* *}$ & $55.31^{* *}$ & $54.81^{* *}$ \\
\hline & $(4.98)$ & $(4.98)$ & $(4.98)$ & $(4.98)$ \\
\hline \multirow[t]{2}{*}{ Mother's age ${ }^{2}$} & $-0.89^{* *}$ & $-0.89^{* *}$ & $-0.89^{* *}$ & $-0.89^{* *}$ \\
\hline & $(0.08)$ & $(0.08)$ & $(0.08)$ & $(0.08)$ \\
\hline \multirow[t]{2}{*}{ Intercept } & $1,216.00^{* *}$ & $1,288.00^{* *}$ & $1,019.00^{* *}$ & $1,125.00^{* *}$ \\
\hline & $(215.60)$ & $(217.10)$ & $(221.40)$ & $(218.60)$ \\
\hline Observations & 53,879 & 53,879 & 53,879 & 53,879 \\
\hline $\mathrm{R}^{2}$ & 0.069 & 0.069 & 0.069 & 0.070 \\
\hline
\end{tabular}

Note: Regressions control for conception year and month interaction fixed effects, day of the week at birth, parity, and daily mean rainfall.

${ }^{\dagger} p<0.10 ;{ }^{*} p<0.05 ;{ }^{* *} p<0.01$. 


\section{A.3 Sample Truncation Based on Gestational Age at Birth}

Research on the effects of pollution on birth weight often include both pre-term (with gestational age less than 37 weeks) and full-term births (Klepac et al. 2018; Stieb et al. 2012). Some studies restrict the analytic sample to full-term births. Full-term sample selection may be important for creating a balanced sample to study the differential effects of pollution during different trimesters (Morello-Frosch et al. 2010) or each month of gestation (Huang et al. 2020). In this paper, we are interested in the average exposure effects from ambient pollution and extreme temperature throughout the course of pregnancy and do not estimate gestation-specific effects. A.1

In the text, we focus on the distribution of birth weights. Following Abrevaya (2001), Firpo, Fortin, and Lemieux (2009), and Koenker and Hallock (2001), we focus on all live singleton births and do not truncate based on gestational age. Gestational age in our sample ranges from 171 to 319 days. While we believe it is important to analyze the full distributional outcomes without gestational truncation, to facilitate comparisons to papers that do impose gestational truncation, in Table A.5, we conduct the same estimation with the same variables as in Table 3, but now restrict our sample to only individuals with gestational age longer than 36 weeks.

The main results in Table A.5 are similar in directions but smaller in magnitudes than the results in Table 3: we continue to find negative associations between pollution and extreme temperatures and birth weight, and find that mothers' college education status is associated with reduced vulnerability to ambient air pollution and extreme heat exposures. ${ }^{\text {A. }}{ }^{2}$ In particular, we find a $1 \mu \mathrm{g} / \mathrm{m} 3$ increase in average daily $\mathrm{PM}_{10}$ potential exposure during pregnancy is associated with an 8.85 gram reduction of birth weight (s.e. 1.56) in Table A.5 column 1, but the same increase is associated with a 17.83 gram reduction of birth weight (s.e. 2.27) in Table 3 column 1. Additionally, we find a maternal college education and $\mathrm{PM}_{10}$ interaction coefficient of 0.72 (s.e. 0.59) in Table A.5 column 2 and of 1.95 (s.e. 0.68) in Table 3 column 2. Corresponding

\footnotetext{
A.1 In Equations (1) and (2), we implicitly assume that the effects of pollution and extreme temperature exposures are the same across gestational periods. Given our sample and location constraints, we do not have sufficient power to identify quantile- and gestation-period-specific estimates.

A.2 In both Tables 3 and A.5, we find a weak negative coefficient for the maternal-college-education and extremecold interaction variable. The coefficient is not significant in Table 3 and weakly significant in Table A.5. As shown in Table 5, these relationships fluctuate between weakly positive and negative across the quantiles for results without gestational restrictions. Quantile results with gestational restrictions are similar.
} 
quantile regression results with full-term birth also show similar patterns as in Tables 4 and 5 .

\section{A.4 Low Birth Weight, Preterm, and Small for Gestational Age}

In the text we focus on a continuous measure of birth weight. But in some cases studies focus on related binary variables: low birth weight (birth weight under 2500 grams), preterm (gestational age less than 37 weeks), and small for gestational age (1 is defined as those with birth weight under $10 \%$ in sex-and gestational-age specific distributions). The three binary outcome division strategies could be interpreted geometrically. With gestational-age along the xaxis and birth-weight along the y-axis, low birth weight cuts the data horizontally, preterm cuts the data vertically, and small-for-gestational-age cuts the data diagonally. While each strategy generates valuable outcomes of interest, these data-reduction strategies eliminate much of the distributional variations in the data and preclude quantile analysis.

In this section, to facilitate comparison of our results to papers that focus on these binary outcomes, we present regression results for low birth weight, preterm and small for gestational age in Tables A.6 and A.7. Tables A.6 and A.7 differ from Table 3 by replacing least-squares with logistic regressions and replacing birth weight with binary outcome variables, but the same right-side specifications are used. Table A.6 presents results as marginal effects, and Table A.7 presents results as odds-ratios. A.3

The results from Tables A.6 and A.7 largely match-up with results from Table 3. First, greater $\mathrm{PM}_{10}$, extreme heat, as well as extreme cold exposure are all associated with increased probabilities for low birth weight, preterm, and small for gestational age. $\mathrm{PM}_{10}$ and and extreme heat have the strongest associations with preterm, extreme cold has the strongest association with low birth weight, and the environmental measures are positively but not significantly associated with higher chance for small for gestational age. Second, maternal college education is significantly inversely associated with all three binary outcomes: its strongest association is with low birth weight and its weakest association is with small for gestational age. Third, we find that

A. 3 From the summary statistics in Table 1, 6\% of the analytical sample have low birth weight (7\% for high school educated, and $4 \%$ for college educated), $7 \%$ of the analytical sample are borne preterm ( $8 \%$ for high school educated, and $5 \%$ for college educated), and $9 \%$ are small for gestational age (10\% for high school educated, and $8 \%$ for college educated). 
Table A.5: OLS regression analysis of birth weight with interactions of ambient $\mathrm{PM}_{10}$ and extreme temperature with maternal education. Using only full-term births.

\begin{tabular}{|c|c|c|c|c|}
\hline \multirow[b]{3}{*}{ Variable } & \multicolumn{4}{|c|}{ Varying cutoffs of extreme temperature exposures } \\
\hline & \multicolumn{2}{|c|}{1 percent cutoff } & \multicolumn{2}{|c|}{2.5 percent cutoff } \\
\hline & (1) & (2) & (3) & (4) \\
\hline \multicolumn{5}{|c|}{ Environmental exposure variables } \\
\hline \multirow[t]{2}{*}{$\mathrm{PM}_{10}$} & $-8.85^{* *}$ & $-9.14^{* *}$ & $-7.70^{* *}$ & $-8.05^{* *}$ \\
\hline & $(1.56)$ & $(1.58)$ & $(1.57)$ & $(1.60)$ \\
\hline \multirow[t]{2}{*}{ Extreme heat } & -8.56 & -10.37 & 0.15 & -0.71 \\
\hline & $(6.68)$ & $(6.78)$ & $(3.52)$ & $(3.58)$ \\
\hline \multirow[t]{2}{*}{ Extreme cold } & $-16.54^{*}$ & $-14.19^{*}$ & $-12.69^{* *}$ & $-11.61^{* *}$ \\
\hline & $(6.99)$ & $(7.12)$ & $(3.04)$ & $(3.09)$ \\
\hline \multicolumn{5}{|c|}{ Education and environmental exposure interactions } \\
\hline \multirow[t]{2}{*}{ College educated } & $12.33^{* *}$ & -35.51 & $12.49^{* *}$ & -44.00 \\
\hline & $(3.98)$ & $(47.06)$ & $(3.98)$ & $(49.35)$ \\
\hline \multirow[t]{2}{*}{ College $x \mathrm{PM}_{10}$} & & 0.72 & & 0.89 \\
\hline & & $(0.59)$ & & $(0.62)$ \\
\hline \multirow[t]{2}{*}{ College $\mathrm{x}$ extreme heat } & & 4.15 & & 1.96 \\
\hline & & $(2.60)$ & & $(1.51)$ \\
\hline \multirow[t]{2}{*}{ College $\mathrm{x}$ extreme cold } & & $-7.54^{\dagger}$ & & $-3.65^{*}$ \\
\hline & & $(4.17)$ & & $(1.67)$ \\
\hline \multicolumn{5}{|l|}{ Control variables } \\
\hline \multirow[t]{2}{*}{ Male } & $111.10^{* *}$ & $111.10^{* *}$ & $111.00^{* *}$ & $111.00^{* *}$ \\
\hline & $(3.48)$ & $(3.48)$ & $(3.47)$ & $(3.47)$ \\
\hline \multirow[t]{2}{*}{ Mother's age } & $39.56^{* *}$ & $39.28^{* *}$ & $39.52^{* *}$ & $39.27^{* *}$ \\
\hline & $(4.26)$ & $(4.26)$ & $(4.26)$ & $(4.26)$ \\
\hline \multirow[t]{2}{*}{ Mother's age ${ }^{2}$} & $-0.60^{* *}$ & $-0.59^{* *}$ & $-0.60^{* *}$ & $-0.59^{* *}$ \\
\hline & $(0.07)$ & $(0.07)$ & $(0.07)$ & $(0.07)$ \\
\hline \multirow[t]{2}{*}{ Intercept } & $2,193.00^{* *}$ & $2,217.00^{* *}$ & $2,131.00^{* *}$ & $2,159.00^{* *}$ \\
\hline & $(170.90)$ & $(171.90)$ & $(171.90)$ & $(173.10)$ \\
\hline Observations & 49,973 & 49,973 & 49,973 & 49,973 \\
\hline $\mathrm{R}^{2}$ & 0.037 & 0.038 & 0.038 & 0.038 \\
\hline
\end{tabular}

Note: Regressions control for conception year and month interaction fixed effects, day of the week at birth, parity, and daily mean rainfall.

${ }^{\dagger} p<0.10 ;^{*} p<0.05 ;{ }^{* *} p<0.01$. 
mothers' college education status is associated with reduced vulnerability to ambient air pollution and extreme heat exposures. Results are similarly for low birth weight and preterm but weaker for small for gestational age. Associations are greater for the extreme heat exposure interaction and are weakly significant for the $\mathrm{PM}_{10}$ exposure interaction. Interesting, we also find a protective effect of maternal college education for the association between extreme cold and preterm.

Table A.6: Marginal-effects from logistic regression analysis of binary birth outcomes with interactions of ambient $\mathrm{PM}_{10}$ and extreme temperature with maternal education.

\begin{tabular}{|c|c|c|c|c|c|c|}
\hline \multirow[b]{3}{*}{ Variable } & \multicolumn{6}{|c|}{ Different binary birth-related outcomes } \\
\hline & \multicolumn{2}{|c|}{ Low birth weight } & \multicolumn{2}{|c|}{ Preterm } & \multicolumn{2}{|c|}{ Small for gestational age } \\
\hline & (1) & (2) & (3) & (4) & (5) & (6) \\
\hline \multicolumn{7}{|c|}{ Environmental exposure variables } \\
\hline \multirow[t]{2}{*}{$\mathrm{PM}_{10}$} & $0.0066^{* *}$ & $0.0067^{* *}$ & $0.0080^{* *}$ & $0.0082^{* *}$ & 0.0010 & 0.0011 \\
\hline & $(0.0011)$ & $(0.0011)$ & $(0.0012)$ & $(0.0012)$ & $(0.0010)$ & $(0.0010)$ \\
\hline \multirow[t]{2}{*}{ Extreme heat } & 0.0041 & 0.0053 & $0.0155^{* *}$ & $0.0168^{* *}$ & 0.0064 & 0.0071 \\
\hline & $(0.0048)$ & $(0.0048)$ & $(0.0057)$ & $(0.0057)$ & $(0.0044)$ & $(0.0044)$ \\
\hline \multirow[t]{2}{*}{ Extreme cold } & $0.0156^{* *}$ & $0.0157^{* *}$ & $0.0127^{*}$ & $0.0145^{* *}$ & $0.0094^{*}$ & $0.0087^{\dagger}$ \\
\hline & $(0.0049)$ & $(0.0050)$ & $(0.0053)$ & $(0.0053)$ & $(0.0045)$ & $(0.0046)$ \\
\hline \multicolumn{7}{|c|}{ Education and environmental exposure interactions } \\
\hline \multirow[t]{2}{*}{ College educated } & $-0.0301^{* *}$ & 0.0272 & $-0.0251^{* *}$ & 0.0419 & $-0.0195^{* *}$ & 0.0012 \\
\hline & $(0.0025)$ & $(0.0301)$ & $(0.0026)$ & $(0.0301)$ & $(0.0029)$ & $(0.0346)$ \\
\hline \multirow[t]{2}{*}{ College x $\mathrm{PM}_{10}$} & & $-0.0007^{\dagger}$ & & -0.0006 & & -0.0003 \\
\hline & & $(0.0004)$ & & $(0.0004)$ & & $(0.0004)$ \\
\hline \multirow[t]{2}{*}{ College $\mathrm{x}$ extreme heat } & & $-0.0043^{* *}$ & & $-0.0045^{* *}$ & & -0.0019 \\
\hline & & $(0.0016)$ & & $(0.0016)$ & & $(0.0019)$ \\
\hline \multirow[t]{2}{*}{ College $x$ extreme cold } & & -0.0005 & & $-0.0079^{* *}$ & & 0.0033 \\
\hline & & $(0.0028)$ & & $(0.0029)$ & & $(0.0031)$ \\
\hline \multicolumn{7}{|l|}{ Control variables } \\
\hline \multirow[t]{2}{*}{ Male } & $-0.0125^{* *}$ & $-0.0125^{* *}$ & $0.0060^{* *}$ & $0.0060^{* *}$ & 0.0025 & 0.0024 \\
\hline & $(0.0019)$ & $(0.0019)$ & $(0.0021)$ & $(0.0021)$ & $(0.0025)$ & $(0.0025)$ \\
\hline \multirow[t]{2}{*}{ Mother's age } & $-0.0141^{* *}$ & $-0.0139^{* *}$ & $-0.0144^{* *}$ & $-0.0143^{* *}$ & $-0.0108^{* *}$ & $-0.0107^{* *}$ \\
\hline & $(0.0019)$ & $(0.0019)$ & $(0.0021)$ & $(0.0021)$ & $(0.0028)$ & $(0.0028)$ \\
\hline \multirow[t]{2}{*}{ Mother's age ${ }^{2}$} & $0.0002^{* *}$ & $0.0002^{* *}$ & $0.0003^{* *}$ & $0.0003^{* *}$ & $0.0002^{* *}$ & $0.0002^{* *}$ \\
\hline & $(0.0000)$ & $(0.0000)$ & $(0.0000)$ & $(0.0000)$ & $(0.0000)$ & $(0.0000)$ \\
\hline Observations & 53,879 & 53,879 & 53,879 & 53,879 & 53,879 & 53,879 \\
\hline
\end{tabular}

Note: Regressions control for conception year and month interaction fixed effects, day of the week at birth, parity, and daily mean rainfall.

${ }^{\dagger} p<0.10 ;{ }^{*} p<0.05 ;{ }^{* *} p<0.01$. 
Table A.7: Odds-ratio from Logistic regression analysis of binary birth outcomes with interactions of ambient $\mathrm{PM}_{10}$ and extreme temperature with maternal education.

\begin{tabular}{|c|c|c|c|c|c|c|}
\hline \multirow[b]{3}{*}{ Variable } & \multicolumn{6}{|c|}{ Different binary birth-related outcomes } \\
\hline & \multicolumn{2}{|c|}{ Low birth weight } & \multicolumn{2}{|c|}{ Preterm } & \multicolumn{2}{|c|}{ Small for gestational age } \\
\hline & (1) & (2) & (3) & (4) & (5) & (6) \\
\hline \multicolumn{7}{|c|}{ Environmental exposure variables } \\
\hline \multirow{2}{*}{$\mathrm{PM}_{10}$} & $1.137^{* *}$ & $1.141^{* *}$ & $1.143^{* *}$ & $1.146^{* *}$ & 1.012 & 1.013 \\
\hline & $(0.001)$ & $(0.001)$ & $(0.001)$ & $(0.001)$ & $(0.001)$ & $(0.001)$ \\
\hline \multirow[t]{2}{*}{ Extreme heat } & 1.084 & 1.109 & $1.293^{* *}$ & $1.321^{* *}$ & 1.081 & 1.090 \\
\hline & $(0.102)$ & $(0.105)$ & $(0.122)$ & $(0.125)$ & $(0.058)$ & $(0.059)$ \\
\hline \multirow[t]{2}{*}{ Extreme cold } & $1.357^{* *}$ & $1.360^{* *}$ & $1.235^{*}$ & $1.272^{* *}$ & $1.121^{*}$ & $1.111^{\dagger}$ \\
\hline & $(0.132)$ & $(0.132)$ & $(0.108)$ & $(0.111)$ & $(0.061)$ & $(0.062)$ \\
\hline \multicolumn{7}{|c|}{ Education and environmental exposure interactions } \\
\hline \multirow[t]{2}{*}{ College educated } & $0.554^{* *}$ & 1.704 & $0.660^{* *}$ & 2.000 & $0.790^{* *}$ & 1.014 \\
\hline & $(0.027)$ & (1.004) & $(0.028)$ & $(0.997)$ & $(0.028)$ & $(0.425)$ \\
\hline \multirow[t]{2}{*}{ College x $\mathrm{PM}_{10}$} & & $0.987^{\dagger}$ & & 0.990 & & 0.996 \\
\hline & & $(0.007)$ & & $(0.006)$ & & $(0.005)$ \\
\hline \multirow[t]{2}{*}{ College $\mathrm{x}$ extreme heat } & & $0.920^{* *}$ & & $0.928^{* *}$ & & 0.978 \\
\hline & & $(0.029)$ & & $(0.025)$ & & $(0.023)$ \\
\hline \multirow[t]{2}{*}{ College $\mathrm{x}$ extreme cold } & & 0.990 & & $0.878^{* *}$ & & 1.040 \\
\hline & & $(0.054)$ & & $(0.042)$ & & $(0.039)$ \\
\hline \multicolumn{7}{|l|}{ Control variables } \\
\hline \multirow[t]{2}{*}{ Male } & $0.782^{* *}$ & $0.782^{* *}$ & $1.104^{* *}$ & $1.105^{* *}$ & 1.030 & 1.030 \\
\hline & $(0.029)$ & $(0.029)$ & $(0.038)$ & $(0.038)$ & $(0.031)$ & $(0.031)$ \\
\hline \multirow[t]{2}{*}{ Mother's age } & $0.759^{* *}$ & $0.761^{* *}$ & $0.788^{* *}$ & $0.789^{* *}$ & $0.877^{* *}$ & $0.878^{* *}$ \\
\hline & $(0.028)$ & $(0.028)$ & $(0.028)$ & $(0.028)$ & $(0.030)$ & $(0.030)$ \\
\hline \multirow[t]{2}{*}{ Mother's age ${ }^{2}$} & $1.005^{* *}$ & $1.005^{* *}$ & $1.004^{* *}$ & $1.004^{* *}$ & $1.002^{* *}$ & $1.002^{* *}$ \\
\hline & $(0.001)$ & $(0.001)$ & $(0.001)$ & $(0.001)$ & $(0.001)$ & $(0.001)$ \\
\hline Observations & 53,879 & 53,879 & 53,879 & 53,879 & 53,879 & 53,879 \\
\hline
\end{tabular}

Note: Regressions control for conception year and month interaction fixed effects, day of the week at birth, parity, and daily mean rainfall.

${ }^{\dagger} p<0.10 ;{ }^{*} p<0.05 ;{ }^{* *} p<0.01$. 


\section{B Acquiring Environmental Data}

A wide array of environmental data is available at detailed geographical units across the globe from the the European Centre for Medium-Range Weather Forecasts (ECMWF) at the Copernicus Climate Change Service. Copernicus provides data access via a free and publicly accessible API service. In this appendix section, we describe how we obtained key environmental data used in this paper using Copernicus.

\section{B.1 Data Retrieval}

Copernicus offers a range of data in different formats with similar data request structures. In particular, temperature as well as other environmental data based on observations from across the globe (with reanalysis) are available from the ERA5 Pressure Level as well as the ERA5 Single Level datasets.

\section{B.1.1 Single Data Retrieval Request}

To acquire Chinese data for the particular period in which our birth outcome data are available, we need to specify the appropriate time ranges as well as the geographical coordinates. We retrieve hourly data from every day between the year 2007 and 2012 by specifying the appropriate year, month, day, and time parameters. We specify our data acquisition geographical area as to the south-east of latitude and longitude coordinates (in decimal degrees) $(23.50,113.00)$ and to the north-west of coordinates $(22.25,114.50)$, which covers the broad geographical area that is relevant for our paper. Our specification for the area parameter is therefore $[23.50,113.00,22.25,114.5]$.

Given this information and after registering with Copernicus to obtain an user-specific url and passkey, Source Code 1 provides a API call to acquire temperature data from Copernicus in grib format. 


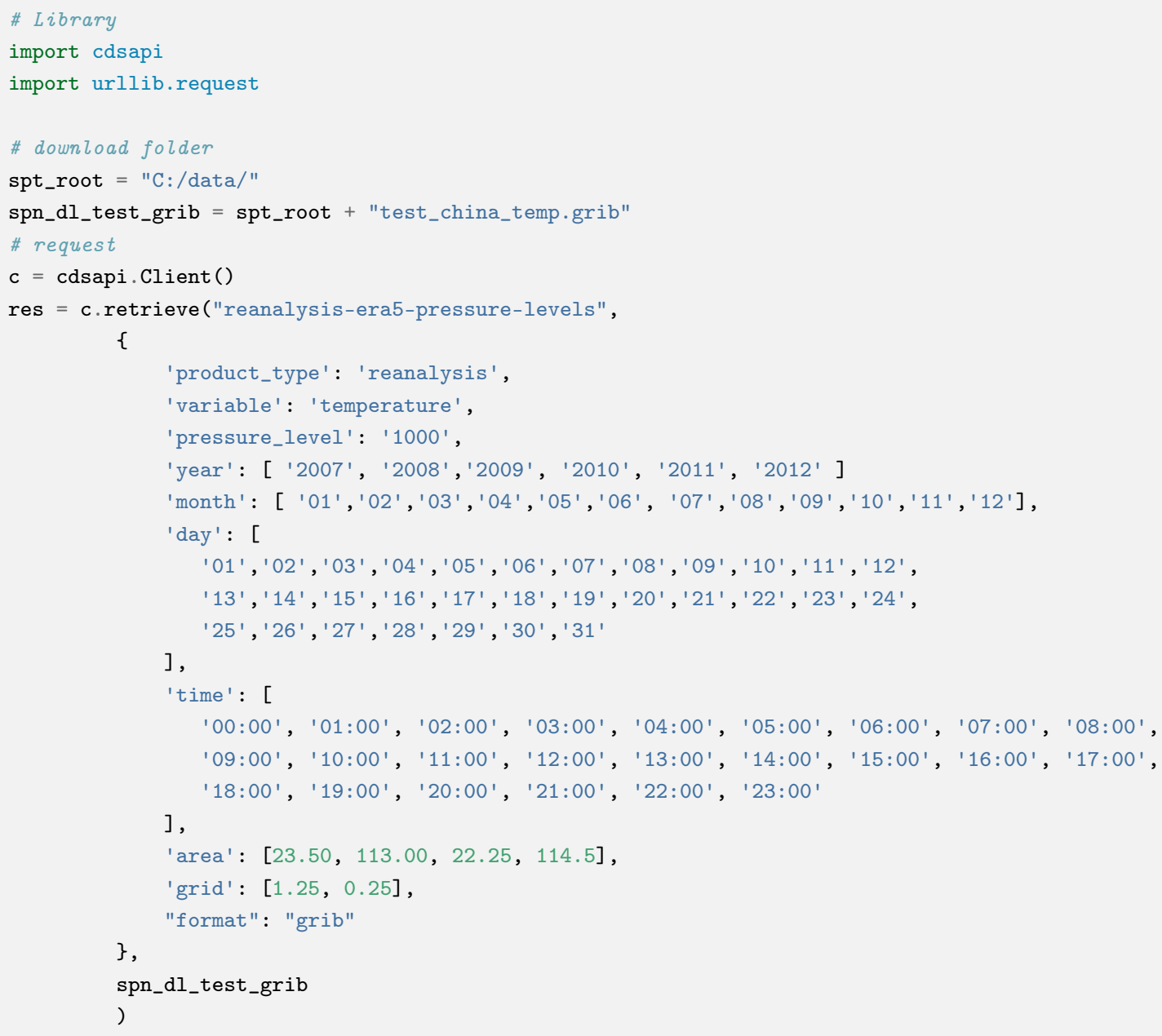

\section{B.1.2 Subdivided Data Retrieval Request}

A challenge to taking full advantage of the data is that, given the fine geographical and time units, the resulting data files can become very large. A single call to acquire all relevant data as shown in the example above can only be implemented on a server with access to Terabytes of storage space.

To deal with this challenge, we divide our API calls into smaller components. We make multiple requests of data at shorter time intervals. Each time we aggregate and process the relevant data before downloading the next set of data. Given the computational resources at our disposal, we download the data at six months intervals, as shown in Source Code 2. Given the computing resources available to the researcher, the time intervals can be further shortened to circumvent computational challenges from using the data. 


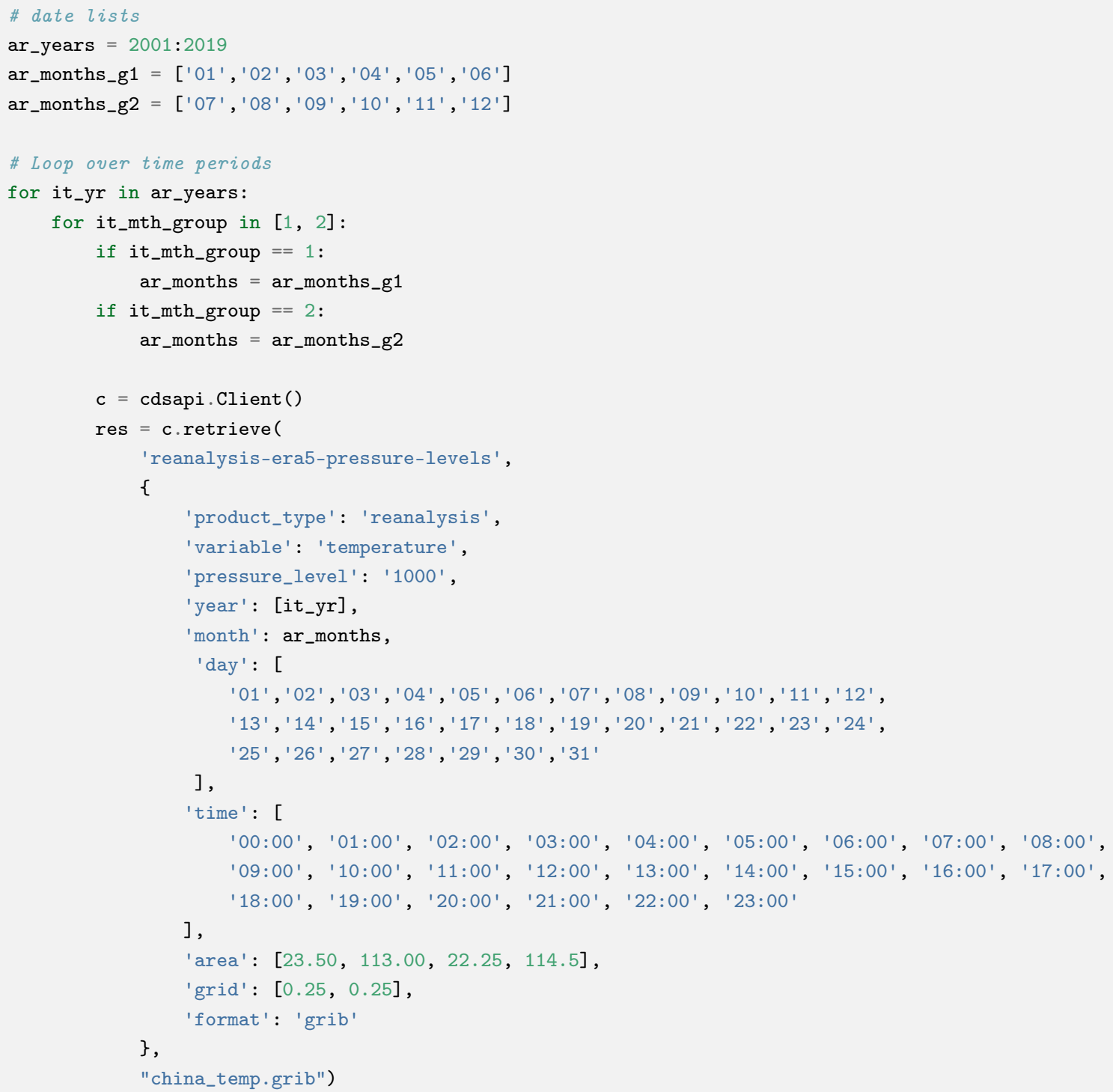

\section{B.2 Data Processing}

The data we download is at finer detail than required by the statistical analysis. For each subperiod of data downloaded, we process the data using a variety of tools. Data in the grib format is processed using the xarray package as shown in Source Code 3. Data in netCDF format is processed using the netCDF4 package as shown in Source Code 4. We store the resulting aggregate data as csv files and combine that with the rest of our child birth outcome data to conduct relevant statistical analysis. 
Source Code 3: Grib Data Processing with xarray

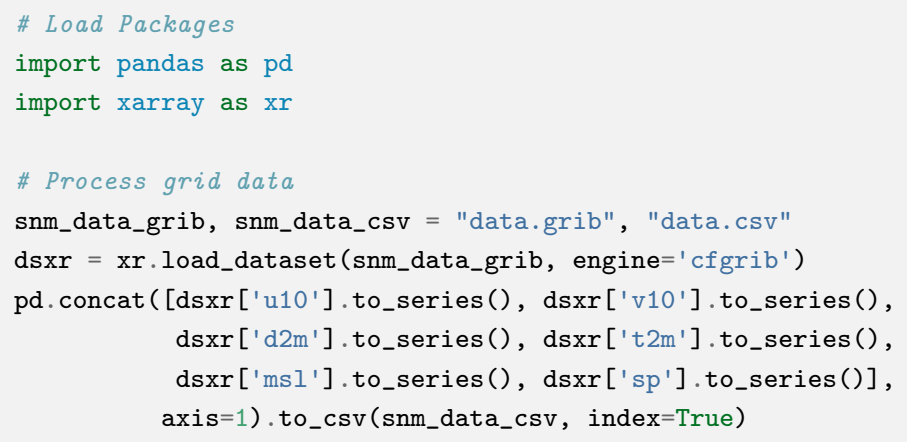

Source Code 4: netcdf Data Processing with netCDF4

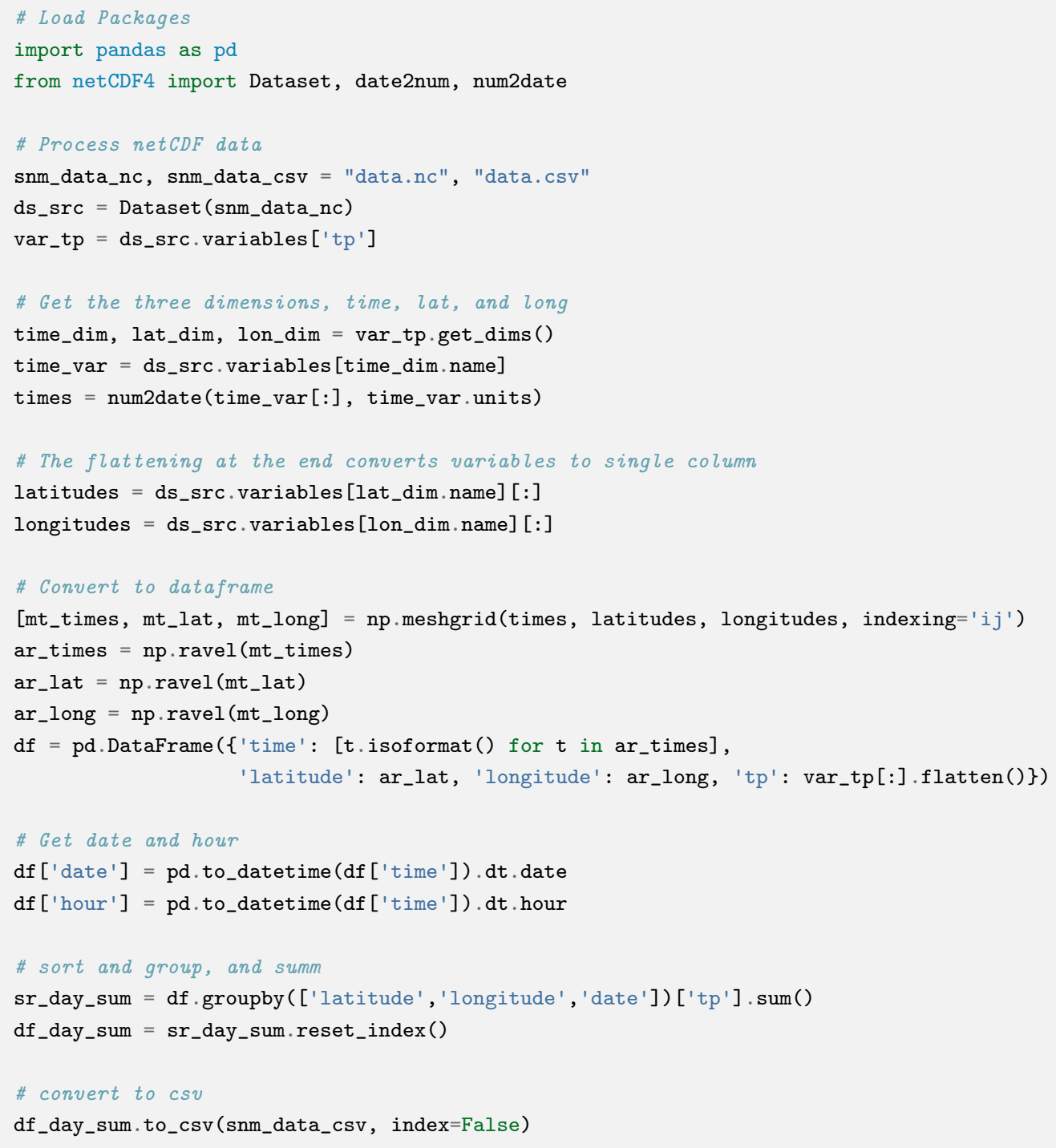

